Article

\title{
Smart Energy Optimization Using Heuristic Algorithm in Smart Grid with Integration of Solar Energy Sources
}

\author{
Urooj Asgher ${ }^{1}{ }^{(}$, Muhammad Babar Rasheed $\left.{ }^{1, *} \mathbb{(}\right)$, Ameena Saad Al-Sumaiti ${ }^{2}{ }^{(D}$, \\ Atiq Ur Rahman ${ }^{3} \mathbb{D}$, Ihsan Ali ${ }^{4, *}$, Amer Alzaidi ${ }^{5}$ and Abdullah Alamri 6 \\ 1 Department of Electronics and Electrical Systems, The University of Lahore, Lahore 54000, Pakistan; \\ urooj.asghar@es.uol.edu.pk \\ 2 Department of Electrical and Computer Engineering, Khalifa University, Abu Dhabi 127788, UAE; \\ ameena.alsumaiti@ku.ac.ae \\ 3 Faculty of Computing and Information Technology, Northern Border University, Rafha 76321, Saudi Arabia; \\ atiq621@gmail.com \\ 4 Faculty of Computer Science and IT, University of Malaya, Kuala Lumpur 50603, Malaysia \\ 5 Department of Information Systems, University of Jeddah, Jeddah 23890, Saudi Arabia; aalzaidi@uj.edu.sa \\ 6 Department of Information Technology, University of Jeddah, Jeddah 23890, Saudi Arabia; \\ amalamri@uj.edu.sa \\ * Correspondence: babarmeher@gmail.com (M.B.R.); ihsanalichd@siswa.um.edu.my (I.A.); \\ Tel.: +92-333-279-7029 (M.B.R.)
}

Received: 31 October 2018; Accepted: 6 December 2018; Published: 14 December 2018

\begin{abstract}
Smart grid (SG) vision has come to incorporate various communication technologies, which facilitate residential users to adopt different scheduling schemes in order to manage energy usage with reduced carbon emission. In this work, we have proposed a residential load management mechanism with the incorporation of energy resources (RESs) i.e., solar energy. For this purpose, a real-time electricity price (RTP), energy demand, user preferences and renewable energy parameters are taken as an inputs and genetic algorithm (GA) has been used to manage and schedule residential load with the objective of cost, user discomfort, and peak-to-average ratio (PAR) reduction. Initially, RTP is used to reduce the energy consumption cost. However, to minimize the cost along with reducing the peaks, a combined pricing model, i.e., RTP with inclining block rate (IBR) has been used which incorporates user preferences and RES to optimally schedule load demand. User comfort and cost reduction are contradictory objectives, and difficult to maximize, simultaneously. Considering this trade-off, a combined pricing scheme is modelled in such a way that users are given priority to achieve their objective as per their requirements. To validate and analyze the performance of the proposed algorithm, we first propose mathematical models of all utilized loads, and then multi-objective optimization problem has been formulated. Furthermore, analytical results regarding the objective function and the associated constraints have also been provided to validate simulation results. Simulation results demonstrate a significant reduction in the energy cost along with the achievement of both grid stability in terms of reduced peak and high comfort.
\end{abstract}

Keywords: demand side management; demand response; appliances scheduling; real-time pricing; inclining block rate; genetic algorithm; renewable energy sources

\section{Introduction}

The growing energy demand has led the researchers to establish a new energy management mechanism or to find alternate energy resources. For this purpose, the utility is transforming its 
infrastructure into smart grids (SGs) by using bi-directional communication technologies to make intelligent decisions [1,2]. For bi-directional flow of information between energy generators and users, a reliable and effective communication infrastructure is required in SGs [3,4]. In doing so, SG can provide more benefits to end users such as cost saving, reduction in brownouts and surges, energy consumption controlling through smart meters (SMs), energy consistency and protecting the environment with integration of RESs [5,6]. In this way, the establishment of SG can be additionally elevated by utilizing demand side management (DSM) methods [7,8]. DSM mechanisms have been adopted to manage the load demand by either convincing consumers to change their consumption patterns $[9,10]$ or to reduce the load demand. Furthermore, DSM been designed to motivate consumers to utilize less energy and pinnacle hours or to move time of energy utilization from pinnacle schedule vacancies to off-top availabilities [11,12]. To adopt DSM mechanisms, utility has introduced a demand response (DR) mechanism $[13,14]$ to further facilitate energy consumers to modify their consumption patterns. In response, they can get incentives in terms of bill reduction. However, DR programs can be further characterized into two broad categories: incentive-based and price-based [15]. Generally, the DR can change the load demand in response to the price policies provided by the utility $[16,17]$. Therefore, among all price based DR programs, RTP has a higher adaptability than other pricing schemes, i.e., time of use (TOU), critical peak pricing (CPP) and day ahead pricing (DAP). Furthermore, it is more promising to combine various loads at a moderately low peak price time slot $[18,19]$. Then, moving all loads from on-peak hours to off-peak hours may disturb consumer comfort along with high PAR [20,21]. In literature, various researchers have proposed numerous methods to manage load demand with the objective of cost and discomfort minimization with rebound peaks, which are caused by considering cost reduction as a primary objective [22,23]. However, there are still gaps to be fulfilled by developing optimal mechanisms having the ability to handle uncertainties and limitations. Thus, there is a need for such types of mechanisms that can handle all respective constraints and limitations while preserving user comfort and rebound peaks. In light of the aforementioned limitations, we have proposed an efficient mechanism to manage the load demand while considering user comfort and cost reduction objectives to prioritize one objective on other, which is decided by the customers. Then, the customers having cost reduction as a primary objective can enhance their bill, while compromising their comfort and vice versa. To further manage the load demand and rebound peaks occurring when a high load is shifted to off-peak hours, RES has been utilized. A part of this work is already published in [24]. The main contributions of our work can be listed as follows:

\subsection{Contributions}

- This work proposes an efficient load management mechanism which takes into consideration: length of operation time (LOT), electricity prices, user preferences, minimum waiting cost and integration of RESs.

- To reduce the probability of rebound peaks while scheduling, load has been categorized on the basis of: (I) customer requirements and (II) mathematical models. Then, a multi-objective optimization problem has been formulated and solved by using GA (Section 7).

- To achieve the objective of cost and user discomfort reduction, simultaneously, a combined pricing model IBR-RTP (Section 4.2.1) is used which provides the priority to users to modify their requirements, i.e., comfort or cost reduction. To analyse the performance of proposed mechanism, various test cases have been implemented and tested via analytical and simulation results. Furthermore, we also integrate the solar energy to further reduces the electricity cost in high peak hours to ensure un-interruptible supply of electricity.

- Finally, convergence results are obtained to check the performance of GA, and analytical and simulation results are obtained to validate the effectiveness of proposed mechanism. It is evident from the results that proposed mechanism effectively manages the load demand while taking customer preferences. 
The remaining section paper is organised as follows. Related work has been discussed in Section 3 , the system model is explained in Section 4, Section 5 states the problem formulation, and Section 6 presents the simulation results. Conclusions are given in Section 7.

\section{Literature Review}

Related works are characterized into two categories: (1) central energy management; (2) distributed energy management. In order to optimally schedule smart appliances, numerous techniques have been demonstrated in literature. Some of the techniques are conversed as follows:

\subsection{Central Energy Management}

With a centralized coordination, a basic objective is to manage the load by one prevalent element which is an aggregator or the utility $[25,26]$. Centralized coordination can result in powerful outcomes; however, it requires point by point data of homes [27], which is not functional and furthermore tends to cause a substantial calculation burden. Furthermore, users are not happy to see their appliances being controlled by another person [28,29]. In [30], authors utilized the DAP plan to decide the power utilization for every user that fulfilled all constraints. Secondly, they set the demand block according to energy utilization that brings down the cost of energy consumption. In [31], authors used two algorithms, tabu search (TS) and enhanced differential evolution (EDE) with RTP for deferrable loads and thermostatically-controlled loads. The primary focus was to get the optimal load schedules. In [32], to manage and control the user energy consumption with TOU, authors provide different services. Thus, the main target is to achieve the lowest cost and energy consumption, when TOU was used with different demand limits, multiple users and priority model. Therefore, bacterial foraging optimization algorithm (BFOA) and bat algorithm were applied. The proposed models showed that DSM played a key role in managing energy usage by scheduling load in off-peak hours. In [18], authors used the mixed integer linear programming (MILP) and proposed an energy management program for an exclusive home that reduces the user bill. Furthermore, the house was equipped with a grid tied rooftop photovoltaic (PV) system with prosumer oriented DSM using the appliance clustering and feed in tariff for the system stability. Therefore, it maximized the user comfort and minimized the energy use of appliances and services in an appropriate manner. Nevertheless, this program increased the installation cost of PV system in a single household. In [33], authors used the dynamic pricing method with appliance scheduling and energy sharing (among SHs) to cut down the electricity bills of the users by using consumer centric (CC) and data analytical demand response (DADR) algorithm. In $[34,35]$, authors applied the differential evolution (DE) algorithm that limits the user frustration and electricity cost for household appliance. On the other hand, lower energy consumption users were affected because of more bill payments on low energy consumption. In [36], authors inspected the issues related to the SG including its cyber-physical security and perils for electric vehicle frameworks security. Fundamentally, these attacks influence the most basic security advantage essentials in the SG, particularly: demolishing the exchanges between the utility and the customers, avoiding the aggressors from obtaining private information, discouraging unapproved customers from changing the data and favouring a customers uniqueness. However, this work [37] overcomes instability issues of the power system due to its physical layer reliability analysis in DSM. In [38], authors applied the pareto optimality in order to cut down the user consumption that can lead to cost saving from $6 \%-12 \%$ without significantly fluctuating the power consumption behaviour of the consumers.

In [39], the artificial neural network (ANN) has been used to tune prediction intervals (PIs), where a GA and simulated annealing algorithms are used to optimally adjust the weights for aggregation. This may decrease the disturbances and uncertainties with forecast. Authors in [40] used recursive least squares (RLS-ESN), particle swarm optimization (PSO-ESN) and harmony search-echo state networks (HS-ESN) algorithms to tune ESN for better prediction. A similar work is reported in [41], where grey wolf optimization (GWO) algorithm is used to tune fuzzy control system parameters in order to reduce computational cost. A complete summary of literature work is depicted in Table 1. 
Table 1. Comparison of proposed work against various related works.

\begin{tabular}{|c|c|c|c|c|c|}
\hline References & Techniques & Objective(s) & Achievement(s) & Limitation(s) & RESs \\
\hline [25] & LP & $\begin{array}{l}\text { Balance the daily } \\
\text { demand that minimize } \\
\text { the peaks }\end{array}$ & $\begin{array}{l}\text { Efficiently overcomes the } \\
\text { peak hour load }\end{array}$ & Time complexity & No \\
\hline [26] & $\begin{array}{l}\text { PSO and } \\
\text { DAP }\end{array}$ & $\begin{array}{l}\text { Limit the power } \\
\text { consumption }\end{array}$ & $\begin{array}{l}\text { Reduces the } \\
\text { consumption cost }\end{array}$ & $\begin{array}{l}\text { User comfort not } \\
\text { considered }\end{array}$ & No \\
\hline$[28,29]$ & TS and EDE & $\begin{array}{l}\text { Schedule the daily load } \\
\text { for cost reduction }\end{array}$ & $\begin{array}{l}\text { Better scheduling is } \\
\text { achieved for minimum } \\
\text { cost }\end{array}$ & $\begin{array}{l}\text { User comfort is } \\
\text { neglected }\end{array}$ & No \\
\hline [30] & $\begin{array}{l}\text { BFOA and } \\
\text { BA }\end{array}$ & Maximize the profit & $\begin{array}{l}\text { Optimal scheduling of } \\
\text { household energy } \\
\text { demand }\end{array}$ & $\begin{array}{l}\text { Slow convergence } \\
\text { rate }\end{array}$ & No \\
\hline [31] & $\begin{array}{l}\text { MILP and } \\
\text { GA }\end{array}$ & $\begin{array}{l}\text { Overcome the cost and } \\
\text { peak load }\end{array}$ & $\begin{array}{l}\text { Minimized the delay } \\
\text { time of appliances and } \\
\text { cost }\end{array}$ & $\begin{array}{l}\text { Increased complexity } \\
\text { of system }\end{array}$ & No \\
\hline$[18,32]$ & $\begin{array}{l}\text { CC and } \\
\text { DADR } \\
\text { algorithm }\end{array}$ & $\begin{array}{l}\text { Increase user comfort } \\
\text { and minimize delay } \\
\text { time }\end{array}$ & $\begin{array}{l}\text { It efficiently reduces the } \\
\text { peak load at the grid to a } \\
\text { great extent }\end{array}$ & $\begin{array}{l}\text { Big data management } \\
\text { and fault tolerance } \\
\text { issues in real time } \\
\text { rate increases } \\
\text { drastically }\end{array}$ & No \\
\hline [33] & DE and PSO & $\begin{array}{l}\text { User frustration and } \\
\text { electricity bill reduction }\end{array}$ & Minimized electricity bill & $\begin{array}{l}\text { Low energy } \\
\text { consumption users } \\
\text { are affected }\end{array}$ & No \\
\hline$[34,35]$ & RLS & $\begin{array}{l}\text { Scheduling based on } \\
\text { forecasting price and } \\
\text { cost minimization }\end{array}$ & $\begin{array}{l}\text { Minimizing peak cost } \\
\text { and increasing user } \\
\text { satisfaction }\end{array}$ & $\begin{array}{l}\text { Delay cost not } \\
\text { considered }\end{array}$ & No \\
\hline$[36,37]$ & $\begin{array}{l}\text { Quasi } \\
\text { random } \\
\text { process }\end{array}$ & $\begin{array}{l}\text { Peak demand valuation } \\
\text { without considering } \\
\text { number of appliances }\end{array}$ & $\begin{array}{l}\text { Recursive method is } \\
\text { used for load scheduling } \\
\text { for peak demand } \\
\text { achievement }\end{array}$ & $\begin{array}{l}\text { User comfort and } \\
\text { peak demand is not } \\
\text { considered which } \\
\text { may cause } \\
\text { overburden utility }\end{array}$ & No \\
\hline [38] & $\begin{array}{l}\text { Pareto } \\
\text { optimality }\end{array}$ & $\begin{array}{l}\text { System reliability \& } \\
\text { security analysis in DSM }\end{array}$ & $\begin{array}{l}\text { Enhanced the reliability } \\
\text { of power system }\end{array}$ & $\begin{array}{l}\text { System reliability in } \\
\text { terms of outage } \\
\text { failure cost not } \\
\text { considered }\end{array}$ & No \\
\hline
\end{tabular}

$\mathrm{LP}=$ Linear programming, $\mathrm{BA}=$ Bat algorithm.

\subsection{Distributed Energy Management}

Distributed demand-side energy management system among users that takes advantage of a two-way digital communication infrastructure is envisioned in the future SG [42-45]. In $[45,46]$, authors used the wind driven optimization (WDO) technique for maximization in user comfort and the main limitation of such a work is that maintenance and installation costs of RESs was not considered. In $[47,48]$, authors used the PSO algorithm to find out optimal energy mixing rates that can minimize daily energy cost of a renewable micro-grids (MGs) under energy balance and anti-islanding constraints. In DSM, the sparse load shifting is a scheduling problem introduced for smart users. In sparse load interruption program, a nash equilibrium (NE) and newton method (NM)are used [49,50]. Through this, maximum user comfort and electricity bill achievements are attained. In [51,52], authors focused on more challenging situations in which electric appliances operations are non-shiftable power and cost of electricity change with the load of the overall grid, and the generation from renewable is ambiguous. Nowadays, solar systems are broadly available. Therefore, every consumer can have a PV system and a storage supply to achieve the individual energy demand. The proposed scaleable and robust demand side management (SRDSM) algorithm entails two parts: in the first part, electricity cost is reduced for all consumers through scheduling. In the second part, cost is further reduced by using the RESs 
and power management algorithm, where a column and constraint generation (C\&CG) mechanism is used to solve a cost minimization problem. In [53,54], the researchers aim to improve the system efficiency with the help of RESs and home energy storage system (HESS) in an SG. RESs support the SG in terms of energy production in a place where the energy consumption is increasing day by day. Therefore, HESS provides a good source to improve the power quality of energy produced by RESs. For an energy storage system, batteries and ultra-capacitor units are used when considering solar power generation. To attain the desired results, maximum power point tracking (MPPT) algorithm is used [55]. Under the projection of the proposed algorithm, it is possible to minimize supply demand mismatch while reducing the operational costs to increase the system efficiency [56]. The suggested plan provides the best desired results; however, it increases the overall cost of the grid connected system. In [57], authors used the nonlinear programming (NLP) and optimal flow (OPF) for cost minimization with PV inverters. In [58], authors considered the particular qualities of week-ahead and day-ahead DSM plan, where a multi-time-scale based DSM booking approach is proposed. With the accessible recorded client load information from advanced metering infrastructure framework, it is exhibited that the proposed dynamic situation age strategy can better catch qualities of indeterminate loads by mimicking self-vulnerability of burdens at a specific time and also vulnerability connections among numerous heaps at various time moments. In [59], authors used the C\&CG method along with coordination of distributed generation units within individual MGs for daily energy demand cost is reduction. However, C\&CG is an iterative method, and that is why computational complexity is increased. In [16], Nash theorem was used to minimize electricity and electric vehicles cost with the integrated RESs. The complete summary of literature work of distributed generation is depicted in Table 2.

Table 2. Summarized literature work for distributed energy management.

\begin{tabular}{|c|c|c|c|c|c|}
\hline References & Techniques & Objective(s) & Achievement(s) & Limitations & RES \\
\hline$[45,46]$ & $\mathrm{ACO}$ & $\begin{array}{l}\text { Single and multiple } \\
\text { home appliance } \\
\text { scheduling using } \\
\text { knapsack problem }\end{array}$ & $\begin{array}{l}\text { Minimize cost, and } \\
\text { maximize comfort with } \\
\text { RES }\end{array}$ & $\begin{array}{l}\text { RES installation cost } \\
\text { is not calculated }\end{array}$ & Yes \\
\hline$[47,48]$ & PSO & $\begin{array}{l}\text { To find out optimal } \\
\text { energy mixing rates } \\
\text { that can minimize daily } \\
\text { energy cost of a } \\
\text { renewable MGs with } \\
\text { RESs }\end{array}$ & $\begin{array}{l}\text { Reduction in cost and } \\
\text { discomfort }\end{array}$ & $\begin{array}{l}\text { low convergence } \\
\text { rate of algorithm }\end{array}$ & Yes \\
\hline$[49,50]$ & $\begin{array}{l}\text { NE and } \\
\text { NM }\end{array}$ & $\begin{array}{l}\text { Sparse load } \\
\text { interruption with } \\
\text { increment in } \\
\text { convergence rate }\end{array}$ & $\begin{array}{l}\text { Minimize the customer } \\
\text { discomfort and } \\
\text { achieved better } \\
\text { convergence rate }\end{array}$ & $\begin{array}{l}\text { The cost of peak } \\
\text { hours are not } \\
\text { minimized and PAR } \\
\text { not considered }\end{array}$ & Yes \\
\hline [51] & $\begin{array}{l}\text { C\&CG and } \\
\text { SRDSM } \\
\text { algorithms }\end{array}$ & $\begin{array}{l}\text { Cost minimization with } \\
\text { RESs and batteries }\end{array}$ & $\begin{array}{l}\text { Minimize the cost of all } \\
\text { consumers }\end{array}$ & $\begin{array}{l}\text { Only considers the } \\
\text { total load cost, peak } \\
\text { cost are ignored and } \\
\text { overall cost of } \\
\text { system is increased }\end{array}$ & Yes \\
\hline$[52,53]$ & $\begin{array}{l}\text { MPPT } \\
\text { algorithm }\end{array}$ & $\begin{array}{l}\text { Energy storage with the } \\
\text { integration of RESs by } \\
\text { using HESS. }\end{array}$ & $\begin{array}{l}\text { Increase the efficiency } \\
\text { of batteries from high } \\
\text { frequency of ripple } \\
\text { currents }\end{array}$ & $\begin{array}{l}\text { Increased the overall } \\
\text { system cost }\end{array}$ & Yes \\
\hline$[54,55]$ & $\begin{array}{l}\text { NLP and } \\
\text { OPF }\end{array}$ & $\begin{array}{l}\text { Cost minimization with } \\
\text { PV inverters }\end{array}$ & $\begin{array}{l}\text { Impressive cost } \\
\text { reduction }\end{array}$ & $\begin{array}{l}\text { Increase system } \\
\text { complexity }\end{array}$ & Yes \\
\hline
\end{tabular}


Table 2. Cont.

\begin{tabular}{llllll}
\hline References & Techniques & Objective(s) & Achievement(s) & Limitations & RES \\
\hline 56,57$]$ & $\begin{array}{l}\text { Optimal } \\
\text { multi } \\
\text { timescale } \\
\text { technique }\end{array}$ & $\begin{array}{l}\text { Week-ahead DSM } \\
\text { scheduling }\end{array}$ & $\begin{array}{l}\text { Accomplishing the } \\
\text { ideal DSM conspire } \\
\text { with the questionable } \\
\text { client power request }\end{array}$ & $\begin{array}{l}\text { User priority is } \\
\text { ignored }\end{array}$ & No \\
\hline$[58,59]$ & C\&CG & $\begin{array}{l}\text { Coordination of } \\
\text { distributed generation } \\
\text { units within individual } \\
\text { MGs }\end{array}$ & $\begin{array}{l}\text { Daily energy demand } \\
\text { cost is reduced }\end{array}$ & $\begin{array}{l}\text { C\&CG is an iterative } \\
\text { method so time } \\
\text { complexity is } \\
\text { increased }\end{array}$ & Yes \\
\hline M16] & $\begin{array}{l}\text { Minimize the electricity } \\
\text { and electric vehicles } \\
\text { (EV) cost }\end{array}$ & $\begin{array}{l}\text { Achieved the balance } \\
\text { load demand and } \\
\text { integration of EV with } \\
\text { RESs }\end{array}$ & $\begin{array}{l}\text { User delay cost not } \\
\text { calculated }\end{array}$ & Yes \\
\hline
\end{tabular}

$\mathrm{ACO}=$ Ant colony optimization.

\section{Motivation}

With the advancements in information and communication technology (ICT), energy sector has been revolutionized to integrate new energy resources or to manage the available energy with the objective of reduced carbon emission $[14,21,31,45,46]$. This is due to massive utilization of fossil fuels to manage energy demand leading to high carbon dioxide emissions. To overcome this issue of global concerns, the SG has come to includes advanced communication, optimization and control mechanisms to ensure cleaner production of electricity. Moreover, SG also facilitates the energy retailers and end users to incorporate distributed energy resources and DR programs to achieve the aforementioned objective. In this regard, various optimization algorithms are being developed to manage load demand within given limits and requirements [16,54-62]. In doing so, the common objectives are: reduced carbon emission, electricity cost, and user discomfort, where user discomfort and cost reduction are contradictory objectives, and users have to prioritize one from another. In this way, the required objective could be more complex, as both objectives have to be achieved without compromising end user requirements. The previous works [45-54] are being developed to achieve this objective; however, there is still a need to optimise the given objective, i.e., cost, and rebound peaks, to further improve the results. Hence, by considering consumer and utility requirements, we have proposed a weight based load management mechanism, where users have been given the facility to set their priority level. The proposed work is different from other works such that cost and user discomfort is significantly reduced without creating rebound peaks in the systems. Further details of the proposed work are given in Section 7.

\section{System Model}

An SG introduces a new vision of energy and information flow to create automated energy control and management network with DSM programs [63,64]. The current research in SG majorly focuses on the DSM, DR, and scheduling techniques to enhance the energy efficiency, stability, and power system capacity $[65,66]$. In this research, we focus on price based DSM programs where the most commonly used pricing schemes include: TOU, CPP, IBR and RTP. The hourly change in RTP may additionally replicate the utilities value of generation or the bargain price level. Subsequently, RTP has a substantially better versatility than TOU and CPP [67]. The focus of DSM program is not to overcome electricity demand during on-peak hours; however, even the EP in low-peak hours which may also prevent rebound peaks. Therefore, RTP may reduce electricity cost; however, it may create peaks that bring high PAR in off-top availabilities. Therefore, an amalgamation of RTP with IBR would be used. When energy demand exceeds from certain level or predefined threshold, then electrical price (EP) would be adjusted which is in accordance with minimum and maximum limits. The IBR with RTP model would proficiently reduce the PAR and hence improve the entire system stability. First, 
we adopt a model by taking into consideration four types of household appliances and an effective and simple mode to model them based on LOT, electricity prices during off-peak time slots, user comfort, and cost savings according to their electricity usage (Figure 1). Second, we will use GA that will be utilized as a bench mark function in order to evaluate the performance of energy consumed in homes. Third, an amalgamation of RTP with IBR will be used for electricity cost and PAR reductions. Fourth, integration of RESs which protects the environment from carbon dioxide $\left(\mathrm{CO}_{2}\right)$ emission and reduces the electricity cost.

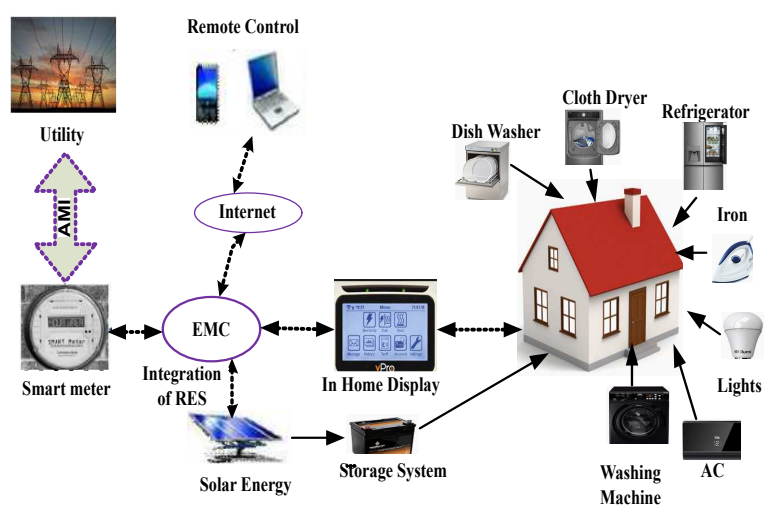

Figure 1. Architecture of energy management system.

\subsection{Categorization of Household Appliances}

In light of RTP+IBR pricing scheme, we consider the optimal scheduling approach for residential load. In the following, four types of appliances are used in the proposed work:

- Non-interruptible (NI): Appliances such as washing machine and cloth dryer work in a cycle and cannot be interrupted once started and must keep running until the end of their cycles.

- Scheduleable (S): Appliances, i.e., dish washer, iron and vacuum cleaner can be scheduled at any time within given horizon.

- User dependent (UD): Appliances, i.e., lights and fans operate according to user presence; if the user is present, the respective appliance would be turned $\mathrm{ON}$ and vice versa.

- Temperature dependent (TD): The working of these appliances, i.e., air-conditioner and refrigerator depend on temperature level. If appliance temperature is low as compared to the specific level, then they will be ON; otherwise, OFF.

To gauge the authorization of the prescribed appliances scheduling patterns, we imitated the day by day energy utilization of family unit appliances. The attributes, i.e., distinctive appliance's, LOT, and the power ratings recorded are listed in Table 3.

Table 3. Appliance parameters detail used in the simulation process [68].

\begin{tabular}{llll}
\hline Category & Appliances & LOT (h.) & Power Ratings (KWh) \\
\hline NI & Load1 & 5 & 2 \\
& Load2 & 11 & 1 \\
\hline S & Load3 & 8 & 2.5 \\
& Load4 & 8 & 3.5 \\
\hline UD & Load5 & 14 & 0.5 \\
\hline TD & Load6 & 7 & 2.5 \\
\hline
\end{tabular}

Let $A_{p}=\{N I, S, U D, T D\}$ denote a set of appliances and for every appliance $\left[a \in A_{p}\right]$ and $P_{a}$ describe the power consumption vector: 


$$
P_{a}=\left[p_{a}^{1}, p_{a}^{2}, \ldots, p_{a}^{24}\right] .
$$

The total power consumption in each hour can be written as:

$$
p_{t}^{T_{h}}=\sum_{h=1}^{T_{h}} x_{a}^{(h)}
$$

where the total time horizon $\left(T_{h}\right)$ can be written as:

$$
T_{h}=[1,2,3, \ldots, 24] .
$$

Our objective is to optimize the power consumption scheduling vector $P_{a}$. Therefore, the total energy consumed by $A_{p}$ appliances for a single day is written as:

$$
E n_{T}=\sum_{t=1}^{\left|T_{h}\right|} \sum_{a}^{\left|A_{p}\right|}\left(x_{t, a}\right) .
$$

\subsection{Electricity Pricing Policies}

As discussed in Section 4.1, an RTP is more effective as compared to TOU and CPP for different appliances' operation. Therefore, RTP gives much adaptability when combined with IBR. In any case, it is highly desirable to focus on real-time constraints of appliances working at a relatively low peak hour. Therefore, using the proposed model that is comprised of RTP and IBR would provide different price variations depending on load consumed.

\subsubsection{RTP with IBR}

We assume that a consumer wants to reduce his/her electricity bill and plans to run a large portion of appliances at 5:00 a.m. However, the electricity price at respective times is comparatively high due to high load demand. As a result, turning ON the load may result in an extra bill, due to variation in electricity price (RTP+IBR). The EP (RTP+IBR) can be expressed as:

$$
p_{(t c h)}= \begin{cases}r^{h}, & \text { if } 0 \leq t_{p c m} \leq t h_{l e v 1} \\ b^{h}, & \text { if } \quad t h_{l e v 1}<t_{p c m} \leq t h_{l e v 2} \\ c^{h}, & \text { if } \quad t_{p c m} \geq t_{l e v 2} .\end{cases}
$$

When $t_{p c m}$ is less than or equal to $t h_{l e v 1}$, then EP in first level is $r^{h}$. Otherwise, the EP would be in $b^{h}$ and $c^{h}$ levels/\$/KWh. As revealed previously, it is necessary for inhabitants to set a few cut-off points for every electric appliances. To reduce cost and PAR, we utilized the RESs with home appliances, which is discussed in Section 5.

\section{Integration of RES}

Renewable generation advancements have been empowered by approach creators during the time in an effort to expand the supportability of electric power framework $[4,69]$. In any case, extortion experienced by confined frameworks as an outcome of the expanding distributed generation infiltration are higher than those accomplished by interconnected frameworks, since they can not rely upon the smoothing impact of an extensive adjusting region and interconnection systems [70,71]. Furthermore, renewable technologies are becoming price-competitive, especially in isolated systems, where diesel and heavy fuel oil generation units dominate the generation mix. Therefore, in this work, we consider the solar Borowy's energy model. 


\subsection{Borowy's Model of the PV System}

Solar PV is the technology used to convert solar energy directly into the electricity. The process of converting sunlight (photons) into electricity (voltage) by using semiconductor material is called PV effect [72]. Borowy's presents a basic model to decide the output energy of a PV module. The Borowy's model expect the utilization of an MPPT. The MPPT is a system in which the grid associated inverters are used to acquire the maximum conceivable power produced by a PV board. In this model, the output power of a PV module is calculated by voltage (V) and current (I) using Equation (14). In Borowy's model, the output power depends on the solar radiance and characteristics of PV module. Therefore, our desired output depends on module capacity due to its characteristics. The total power produced by Borowy's module is $\left(99,460 \times 10^{16}\right)$ [73]. Therefore, a graph of the total power generation and current is shown in Figure 2. To determine the $V_{\text {out }}$ and $I_{\text {out }}$, the Borowy's model can be divided in several parts that are mentioned below:

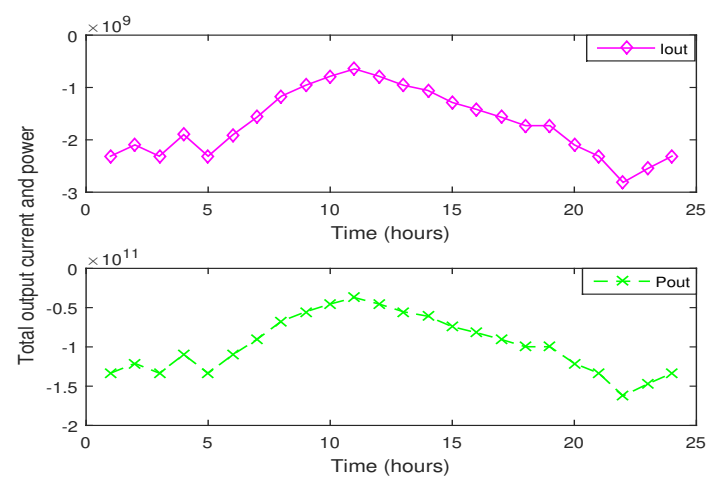

Figure 2. Total output power and current produced by Borowy's model.

$\Delta T$ is change or variation in the temperature which can be determine by the following equations:

$$
\begin{gathered}
\Delta T=T_{\text {cell }}-25, \\
T_{\text {cell }}=T_{\text {amb }}+\left(\frac{N O C T-20{ }^{\circ} \mathrm{C}}{0.8}\right) G .
\end{gathered}
$$

$\Delta I$ is changed or variation in current which depends on solar irradiance and temperature variation:

$$
\begin{gathered}
\Delta I=\alpha\left(\frac{G}{1000}\right) \Delta T+\left(\frac{G}{1000}-1\right) I_{S C}, \\
I_{S C}=G \frac{I_{S C}(C E M)}{1000} .
\end{gathered}
$$

$\Delta V$ is variation in voltage which depends on $\Delta T, \Delta I$, and series resistance:

$$
\begin{gathered}
\Delta V=-\beta \Delta T-R_{s} \Delta I, \\
C_{1}=\left(1-\frac{I_{m p p}}{I_{S C}}\right) \exp \left[\frac{-V_{m p p}}{C_{2} V_{o c}}\right], \\
C_{2}=\frac{\frac{V_{m p p}}{V_{o c}-1}}{\ln \left(1-\frac{I_{m p p}}{I_{S C}}\right)} .
\end{gathered}
$$

The module current is the output current of PV module calculated by the following equation:

$$
I(v)=I_{S C}\left[1-C_{1}\left[\exp \left(\frac{V+\Delta V}{C_{2} V_{o c}}\right)-1\right]\right]+\Delta I,
$$




$$
P_{\text {out }}^{\max }=V I
$$

\section{Problem Formulation}

This section provides the mathematical description of proposed load scheduling problem using RTP and IBR+RTP pricing models. Here, major emphasis is given to optimally find the scheduling patterns of loads within given limits and preferences. It is also considered that residents have set the operating intervals of their loads prior to scheduling, so that the optimization algorithm can find the best optimal solution without violating constraints. Suppose that we have $a$ number of loads to be scheduled in $T_{h}$ hours such that $P_{a}$ is needed in order to meet the energy demand. However, $P_{a}^{\min }$ and $P_{a}^{\max }$ are low and upper bounds of power required. As $T_{h}$ corresponds to the scheduling time interval that is an equally spaced interval of $24 \mathrm{~h}$, so $s t_{a}$ and $e t_{a}$ demonstrate the starting and ending time bounds. Meanwhile, $l t h_{a}$ shows the LOT, i.e., the number of time slots for the operation of appliance " $a$ ". We also define a variable tos $_{a}$ as the working time of appliance " $a$ ". Figure 3 shows a relationship among various factors to express the delay factor.

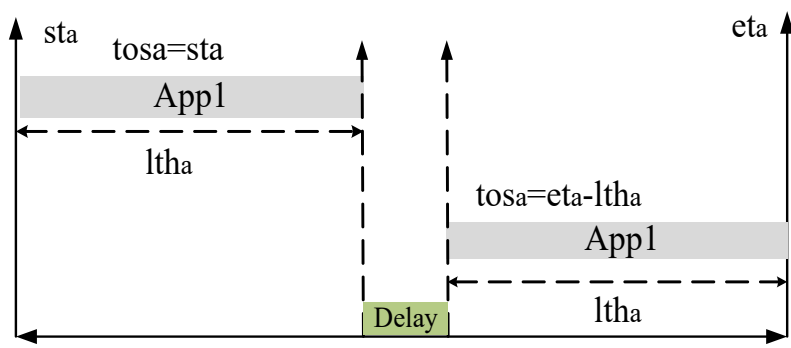

Figure 3. Two appliances' example to show the connections among all factors.

Furthermore, we set the range of operation start time of appliance " $a$ " as a variable, i.e., $\operatorname{tos}_{a}$ can be written as:

$$
\operatorname{tos}_{a} \in\left[s t_{a}, e t_{a}\right] .
$$

If $t \leq t_{o s}$ or $t>e t$, the power consumption of appliance " $a$ " will be zero, where $t_{o s}$ is an appliance start time and $e t_{a 1}$ is a maximum time limit as shown in Figure 3. Otherwise, $P_{a}$ can be written as:

$$
P_{a}^{\min } \leq P_{a} \leq P_{a}^{\max }
$$

Now, $P_{\text {sch }}$ vector would be determined as:

$$
P_{\text {sch }}=E n_{T} \quad \forall h \in T_{h} .
$$

\subsection{Delay Factor (DF)}

A DF is used to separate the occurrence of two events. However, in this work, our aim is to reduce the delay time for smart home users to increase their comfort. Now, DF of appliance " $a$ " is taken into consideration as explained in [61,68,74,75]:

$$
D F_{a}=\frac{t o s_{a}-s t_{a}}{e t_{a}-l t h_{a}-s t_{a}} .
$$

The maximum and minimum numeric values of DF are set to be 1 and 0 . However, if start time of any appliance is $s t_{a}$, then DF would be 0 . If the start time is $e t_{a}$, the DF would be 1 . The sum of DFs for all appliances with the waiting time cost can be modelled as $[61,68,74,75]$ :

$$
q^{D F_{a}}=\frac{\left(\zeta_{a}\right)^{e t_{a}-h}}{p_{t}^{T_{h}}} .
$$


The following model for the waiting parameter for each appliance $a \in A p$. The higher the value of $\zeta_{a}$, the higher will be the cost of waiting:

$$
\sum_{t=1}^{T_{h}} \sum_{a \in A_{p}}\left(q^{D F_{a}}\right)\left(x_{a}^{(h)}\right) .
$$

Here, the delay parameter is $q \geq 0$ for each appliance " $a$ " in any hour $h \in T H$. Thus, $q=0 \forall$ $h<s t_{a}$ and $h>e t_{a}$ as the waiting time can be defined within the valid scheduling interval. Therefore, the waiting cost increases as more energy consumption is scheduled at later hours. The waiting cost increases as the value of $\zeta_{a}$ increases. Therefore, in the final optimization problem, we minimize the electricity consumption cost and " $q$ ".

\subsection{Impact of Control Parameter on Scheduling $\zeta_{a}$}

A user can adjust waiting cost and time by modifying parameter $\zeta_{a}$ for every appliance working in a home. By choosing $\zeta_{a}=1$ for " $a$ ", i.e., $a \in A p$, the load control procedure just attempts to diminish the power charges. Here, we characterize $d_{t}$ for every appliance " $a$ ", as

$$
d_{t}=\frac{\varrho_{a}-s t_{a}}{e t_{a}-s t_{a}}
$$

where $\varrho_{a}>s t_{a}$, considering " $h^{\text {th }}$ " hour with the objective of $x_{a}^{h}=0$. It is obvious that, if the holding time approaches $100 \%$, the energy demand is scheduled in the most recent satisfactory hour $e t_{a}$. As we increase the value of $\zeta$, the electricity cost (total payment) will also increase, while the delay time will decrease as shown in Figure 4. In the proposed work, we choose minimum and maximum values of $\zeta$ as 1 and 1.01, respectively. Then, the impact of $\zeta$ regarding delay time cost can be seen from Figure 4 . Thus, the users have been given priority in such a way that they can optimize the energy usage as per their requirements i.e., either comfort for cost.

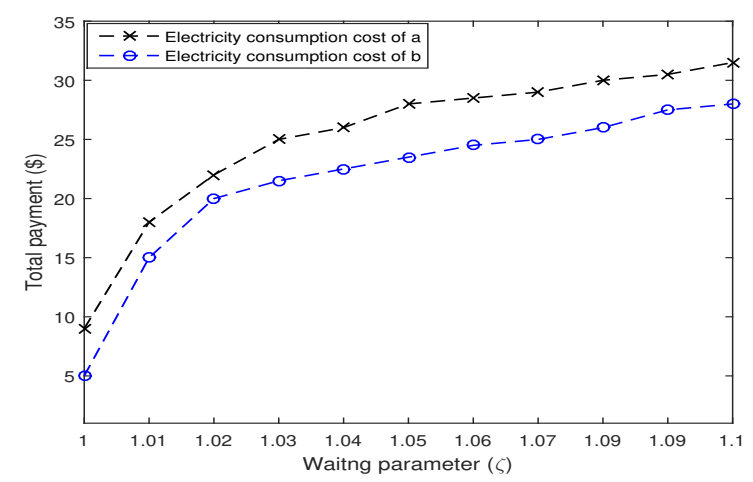

Figure 4. The impact of changing $\zeta$ on electricity cost and delay time. The trade-off is evident. Total cost and delay time versus parameter $\zeta$.

In this section, we formulate an optimization problem that minimizes the total electricity consumption bill while stabilizing the user ease with minimum waiting cost. The purpose of this model is to shift the energy consumption schedules within the residential neighbourhood in order to achieve optimum savings. The purpose is not only to reduce the amount of consumed energy but also to find the optimal energy schedules for each appliance that would reduce the bill and minimize DF. Using the Equations (1) and (2), we can determine the electricity bill in terms of the energy consumption schedules as in Equation (4). A cost effective energy consumption scheduling can be depicted in terms of minimizing the electricity consumption bill of all appliances in the system, as the optimization problem below: 


$$
\operatorname{Minimize}\left(v_{c m p} \cdot\left(P_{\text {sch }}\right)+\mu_{\text {delay }} \cdot\left(D F_{a}\right)\right)
$$

Subject to:

$$
\begin{aligned}
& \operatorname{tos}_{a} \in\left[s t_{a}, e t_{a}-l t h_{a}\right], \\
& \text { ont }_{a} \in\left[\text { stsch }_{a}, \text { etsch }_{a}-\text { lthsch }_{a}\right], \\
& P_{\text {sch }}=\sum_{h=1}^{24} p_{(t c h)}\left(p_{\text {sch }}^{h}\right) \cdot\left(p_{\text {sch }}^{h}\right)-P_{\text {out }}^{\text {max }}, \\
& D F_{a}=\frac{\left(\zeta_{a}\right)^{e t_{a}-h}}{p_{t}^{T_{h}}} \cdot x_{a}^{h},
\end{aligned}
$$

where, Equation (22) gives the objective function aiming at cost minimization, which is modelled as a binary programming problem. In order to control the load and delay cost $v_{c m p}$, a $\mu_{\text {delay }}$ parameter is used in objective function as given in Equation (22). A maximum value of $\mu_{\text {delay }}=1$. Equations (22a) and (22b) represent the scheduling horizon for RTP and RTP+IBR cases, in which the load can be scheduled. Equation (22c) calculates the appliance's energy consumption with the desired scheduling approach according to its operation with the integration of RES for cost saving benefits and user in-dependability. Therefore, an efficient comfort aware energy consumption scheduling optimization problem can be expressed in Equation (22d), where $D F_{a} \in[0,1]$.

\section{Proposed Scheduling Algorithm}

Section 6 demonstrates the minimum constrained optimization problem having linear and nonlinear constraints. In literature, there have been different algorithms (i.e., mathematical, heuristic, robust) used to solve such types of problems [39-42,76,77]. However, the selection of algorithm depends on the nature of problem and user requirements such as highly optimal solution or fast convergence time. As both objectives are contradictory and cannot be achieved at the same time, users thus have to compromise one for the other (i.e., optimality vs. convergence rate). Recently, heuristic algorithms have gained the attention of numerous researchers and industrialists due to their capability of providing feasible solutions within optimal limits [26,30,33,45-48]. Among them, GA is widely adopted due to its fast convergence and accuracy in providing optimal solutions. The complete steps involved in GA optimization, i.e., initiation, fitness function, selection, crossover probability (Pc) and mutation probability ( $\mathrm{Pm}$ ) have been described in Algorithm 1 [77]. Meanwhile, Table 4 provides the control parameters of GA. In this research work, chromosomes represent the ON/OFF state of appliances. The complete steps for load scheduling using GA has been demonstrated in Algorithm 1 , in order to better elucidate the proposed approach. Steps 4-6 describe that RES is first utilized if the energy demand does not exceed the limit, steps 8-14 demonstrate the scheduling patterns being obtained by using GA if the RES does not fulfill the load demand, if the optimized results are not obtained from the current population, step 17 is used, and steps 19-21 are used to describe the formation of new population from parents chromosomes. In each iteration, a new population is generated by using $P_{c}$ and $P_{m}$ because, along with other parameters (i.e., population size, constraints, dataset), the convergence rate of the algorithm depends on the $P_{c}$ and $P_{m}$. Table 4 provides the GA parameters, which are used in this proposed work as given in [78]. 
Table 4. Control parameters used in GA [78].

\begin{tabular}{cc}
\hline Parameters & Values \\
\hline Number of appliances & 6 \\
\hline Max. generation & 500 \\
\hline Population size & 400 \\
\hline Pc & 0.8 \\
\hline Pm & 0.2 \\
\hline
\end{tabular}

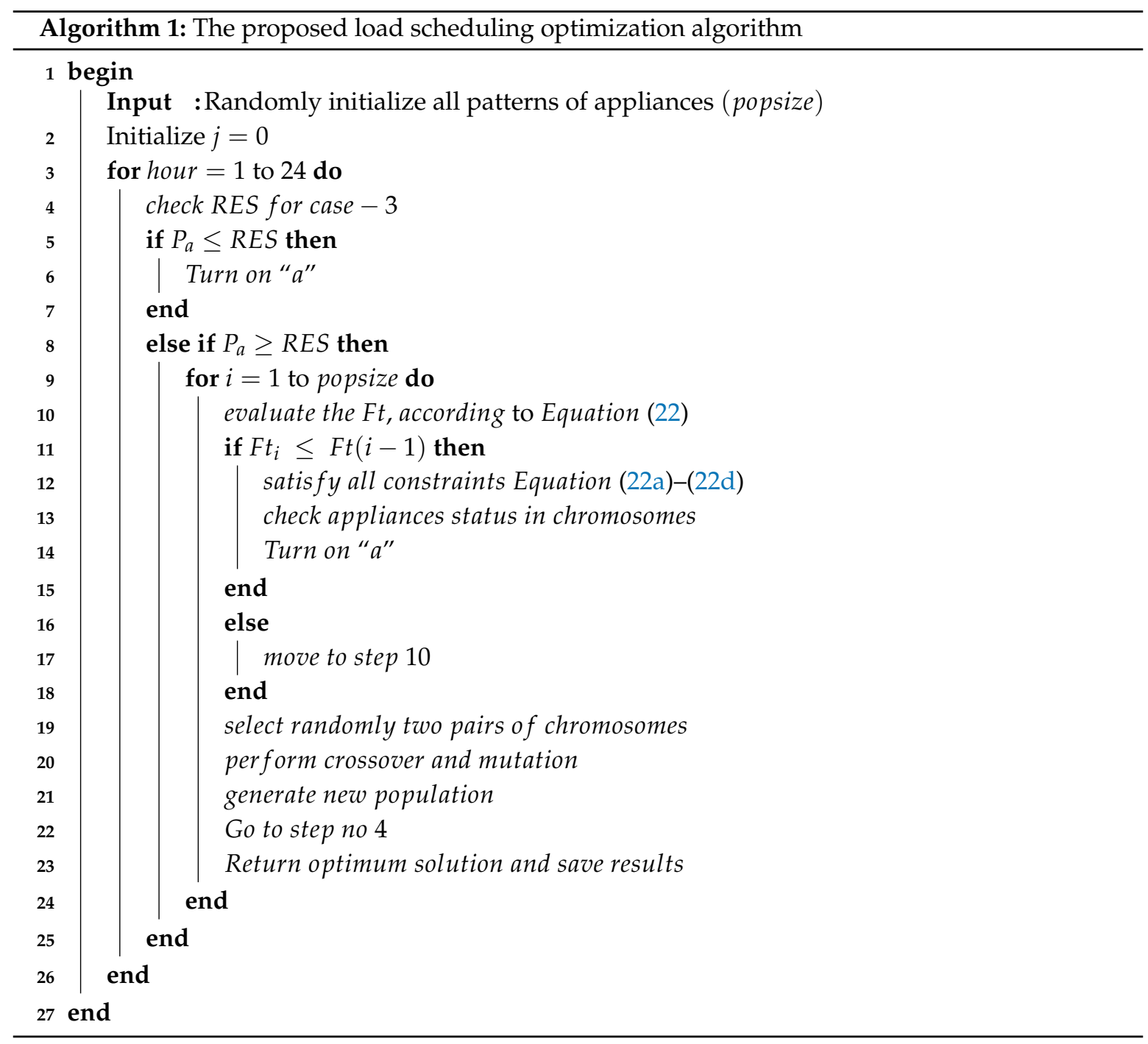

\subsection{Convergence Rate of Algorithm}

In this section, we evaluate the convergence of the proposed algorithm in accordance with the parameters and constraints. The concept of rate of convergence is of practical importance when working with a sequence of successive approximations for an iterative method [78]. Generally, the GA works with an initial population which is taken, randomly. Then, the objective function is evaluated as per given criteria (i.e., cost, delay). For reproduction of new population, we have used: roulette wheel selection criteria, single point $P_{c}$ and $P_{m}$. If we increase the value of $P_{c}$, the convergence rate would be increased, and the high value of $P_{m}$ would probably reduce the quality of optimal solution and can cause premature convergence $[18,79]$. Therefore, in this work, we use test different values of 
$P_{c}$ and $P_{m}$ and select the best values ensuring fast convergence and optimality. Figure 5 shows the convergence plots of GA at different values. Furthermore, in order to avoid premature convergence, we have used a sigma scaling factor. Sigma scaling factor attempts to moderate the selection pressure over time and based on population fitness scores [78]. In our work, we conduct simulations, where we have considered: residence $=1$ and $A_{p}=6$. We can see from Figure 5 that, within 200 iterations, the objective value $p_{(t c h)}$ of algorithm has converged for RTP+IBR scheduled load. Within 300 iterations, the value of $P_{\text {out }}^{\text {max }}$ has converged for the scheduled load with RES. Meanwhile, in [68], the algorithm convergence is missing which seems comparatively high due to small time intervals and incorporation of manually operated appliances.
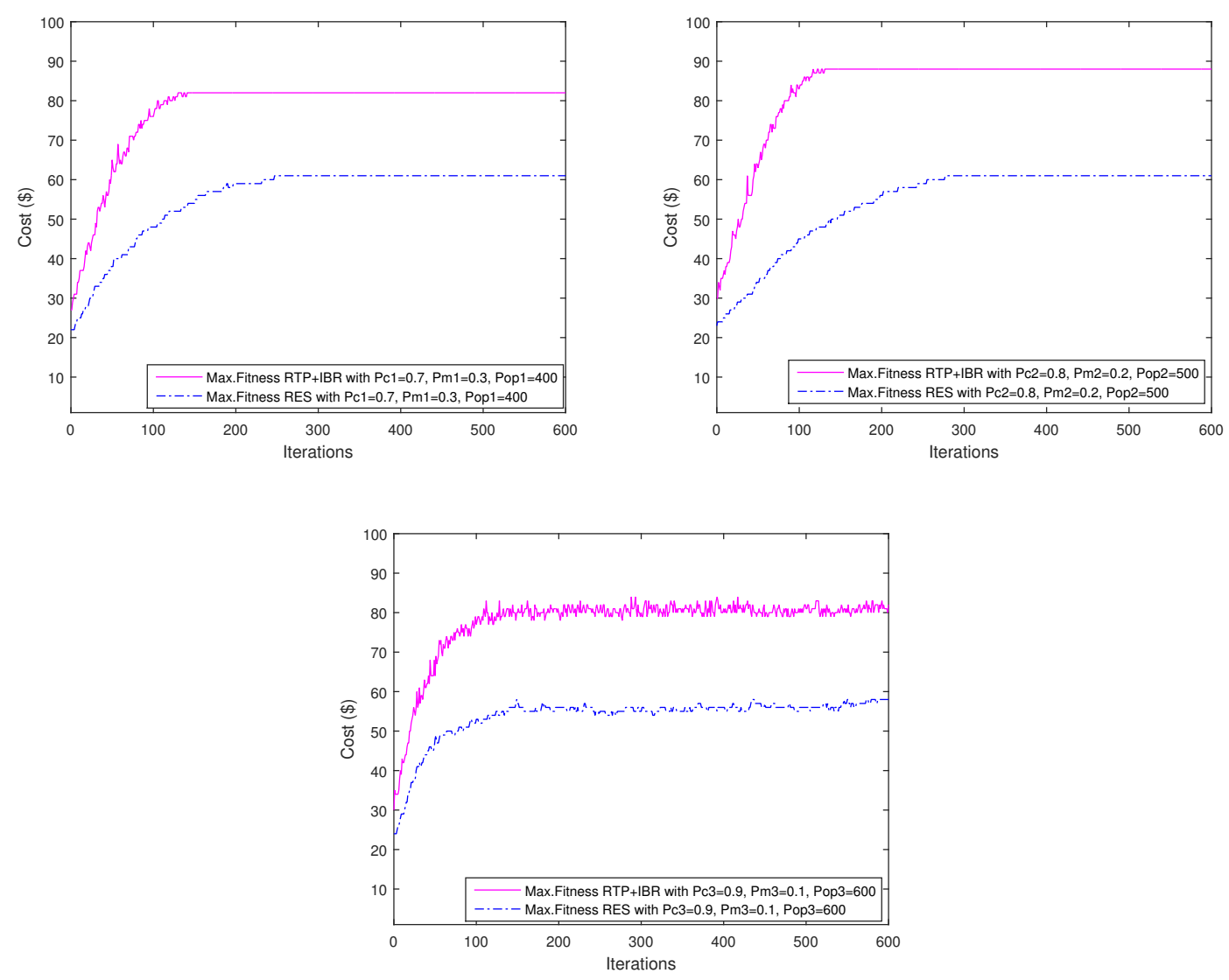

Figure 5. Convergence rate of GA against various parameters, i.e., $P_{c}, P_{m}$ and $p o p_{\text {size }}$ for the scheduled load with RTP+IBR and RTP+RES cases.

\subsection{Feasible Region}

A zone which can be characterized by a particular arrangement of all possible points in which the target fulfils the outcome is called a feasible region. This is the initial set of candidate solutions to the problem [71]. We have obtained the feasible regions of all considered test cases given Section 8.6, in order to validate simulation results.

\subsubsection{Scheduled Load with RTP}

First, we consider the scheduled load with RTP for a single day in which our target is to limit the cost by controlling energy utilization. Therefore, the hourly cost per can be defined as:

$$
C s t_{\text {total }}^{T}=\sum_{a i \in A p, \text { Sch-load }} \operatorname{Lod}_{a i, S c h} \times E P .
$$

We have to minimize the cost of each hour. Thus, objective function is defined as: 


$$
\operatorname{Min}\left(\operatorname{Cst}_{\text {total }}^{T}\right) \text {. }
$$

Subsequently, the respective constraints are:

$\mathrm{C} 1: 0.2 \leq \mathrm{Cst}_{T}^{\text {Sch }} \leq 337.7$,

$C 2: \sigma_{\text {total }} \leq 1.8592 \times 10^{3}$,

C3 $: 1 \leq$ Load $_{T}^{\text {Sch }} \leq 11$.

We consider RTP EP signal whose range is (10.20 to 30.70) \$/KWh. Therefore, Table 5 shows four conceivable events. Furthermore, the maximum unscheduled cost in every hour is $C_{s t}^{\text {Unsch }}=\$ 337.7$. In Figure 6a, the infeasible region is represented by the points (P1, P2, P3, P6 and P4), while the shaded block which is represented by (P1, P2, P5, P6 and P4) is a feasible area. Therefore, the cost in the feasible region is called the feasible/optimum cost of electricity consumption.

Table 5. Cost results against various load and price profiles considering RTP.

\begin{tabular}{cccc}
\hline Event & Load (KWh) & EP (\$/KWh) & Cost (\$) \\
\hline Min- load, Min-EP & 1 & 10.2 & 10.2 \\
\hline Min- load, Max-EP & 1 & 30.7 & 30.7 \\
\hline Max- load, Min-EP & 11 & 10.2 & 112.2 \\
\hline Max- load, Max-EP & 11 & 30.7 & 337.7 \\
\hline
\end{tabular}

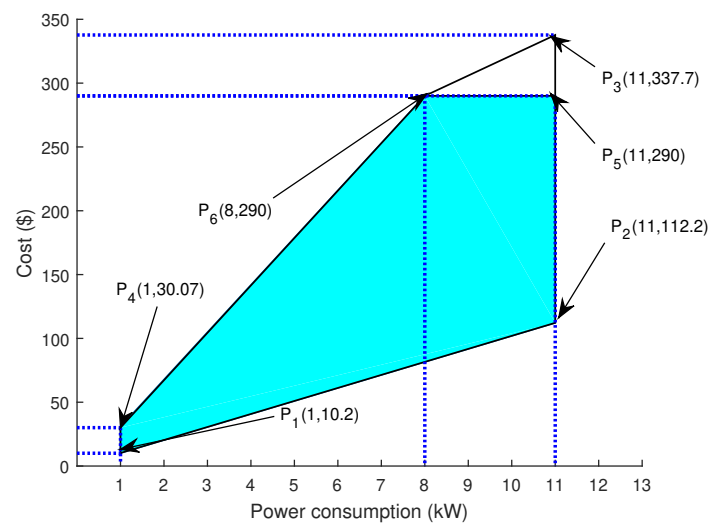

(a)

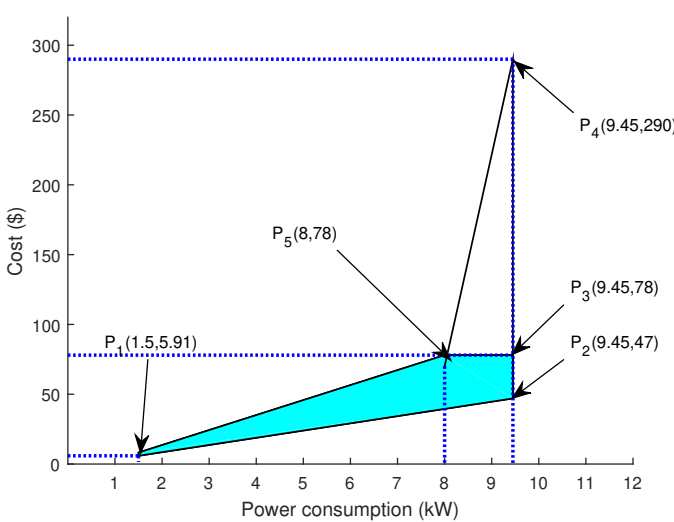

(b)

Figure 6. Feasible region for scheduled load with: (a) feasible region for scheduled load with RTP, and (b) feasible region for scheduled load with RTP+IBR.

\subsection{Scheduled Load with RTP+IBR}

In this case, the objective remains same; however, the limits have been changed in order to improve the reliability of a power system because the pricing tariff has be changed in accordance with the consumption limits. Thus, the cost per hour can be defined as follows:

$$
C s t_{\text {total }}^{T}=\sum_{a i \in A_{p}, \text { Sch-load }} \operatorname{Lod}_{a i, S c h} \times E P .
$$

As we have to minimize the energy consumption cost of each hour, the new objective function is defined as:

$$
\operatorname{Min}\left(\operatorname{Cst}_{\text {tota }} l^{T}\right) \text {. }
$$

The associated constraints for the calculation of feasible regions are given as: $C 1: 0.2 \leq C_{S t}^{\text {SchRTP }} \leq 290$, 
$C 2: \sigma_{\text {tota }} \leq 1.4747 \times 10^{3}$,

C3 $: 1.5 \leq$ Load $_{T}^{\text {Sch }} \leq 9.45$.

Table 6 shows the four events of price for RTP+IBR whose range is (10.20 to 30.70) \$/KWh. In addition, the maximum energy cost in each hour using RTP+IBR mechanism is $\$\left(C_{s} t_{\operatorname{Max}}^{S c h R T P}=290\right)$. In view of these values, we constraints have been characterized in such a way that hourly scheduled load is always less than or equivalent to $\$\left(C s t_{\text {Max }}^{S c h R P}=290\right)$. C1 demonstrates that maximum cost in every hour is $\$ 290$. For this objective, we have scheduled the load such that the cost cannot be more than $\$ 290$. Therefore, the aggregated cost in every day cannot exceed the unscheduled cost as demonstrated in C2. Maximum schedule load using RTP+IBR in a given time slot is $9.45 \mathrm{KWh}$, which is shown in C3. Therefore, the scheduled is always equal or less than this load. In Figure $6 \mathrm{~b}$, the area represented by the points (P1, P2, P3, P6 and P4) gives the cost, while the shaded portion by (P1, P2, $\mathrm{P} 5, \mathrm{P} 6$ and P4) is a feasible region. Therefore, the cost in this region will be feasible in any time slot and it is always less than overall electricity cost.

Table 6. Cost results against various load and price profiles considering RTP+IBR.

\begin{tabular}{cccc}
\hline Event & Load (KWh) & EP (\$/KWh) & Cost (\$) \\
\hline Min-load, Min-EP & 1.5 & 10.2 & 15.3 \\
\hline Min-load, Max-EP & 1.5 & 30.7 & 46.50 \\
\hline Max-load, Min-EP & 9.45 & 10.2 & 112.2 \\
\hline Max-load, Max-EP & 9.45 & 30.7 & 290.11 \\
\hline
\end{tabular}

\section{Simulation Results}

Simulation results are depicted in this section based on DR programs that manage the residential load. Before going towards simulation results and analysis, a description of conventional and smart home users is provided.

\subsection{Conventional Users}

This class of users have no smart technologies like (smart phones, tabs and laptops) and no information about their load management strategy. The unscheduled class users are considered because they have no home energy management planning/solution, no price awareness along with improper load scheduling scheme.

\subsection{Smart Users}

In this class, users have smart home appliances which respond to digital technology i.e., smart phones, tabs and laptops. Therefore, this type of users have home energy management (HEM) structure and RTP signal information in their homes via in home display.

\subsection{Proposed Cases}

Simulation results are achieved for four main cases that are discussed below.

\subsubsection{Unscheduled Case}

This class of users has no information about their load management according to hourly changing electricity price, and that is why they pay more bills.

\subsubsection{Scheduled Case with RTP}

In this class, the home has smart appliances and the HEM system is amended. Therefore, for this class of users, we will use the GA based scheduling plan with RTP information to manage their loads. RTP is a price signal which is obtained from the energy retailers. 


\subsubsection{Scheduled Case with RTP+IBR}

This class of smart users is also based on GA scheduling, which used the combined pricing model i.e., RTP+IBR for effective load management. Complete discussion about these proposed cases are added in the next section.

\subsubsection{Scheduled Case with RES}

For this class of users, the users achieve benefits of the differential pricing plan and use the RES framework ideally to limit the cost. The home that is engaged with RES generation limits the power cost by an extremely remarkable amount by moving the peak load from the grid to RES system.

\subsubsection{Scheduling Pattern of Appliances}

To validate the efficiency of the considered load scheduling scheme, pricing signals that are considered in work and simulation results of all four situations are examined and conferred.

\subsection{Pricing Patterns}

For bill calculation, the RTP pricing signal has been used in the proposed work because the RTP provides more flexibility as compared to other pricing schemes i.e., TOU, CPP and DAP. This is due to the fact that its value changes in each hour as per load consumption. This is why scheduling with RTP for variable loads is easier and effective in cost reduction scenarios, although RTP is an effective pricing schemes where cost reduction is a primary objective. However, RTP can create rebound peaks as all users try to shift their load in low-peak hours. Therefore, to reduce the PAR and bill according to energy consumption, the combined model of RTP+IBR is used. The main purpose of this combined model is to reduce the user consumption cost as well as PAR. These costs are normally perceived well ahead of time by the utility. The combined RTP+IBR model provides flexibility to the potential users aiming at participation in load management programs using DR. Figure 7 demonstrates the typical RTP and IBR signals which can later on be used for the load scheduling mechanism.

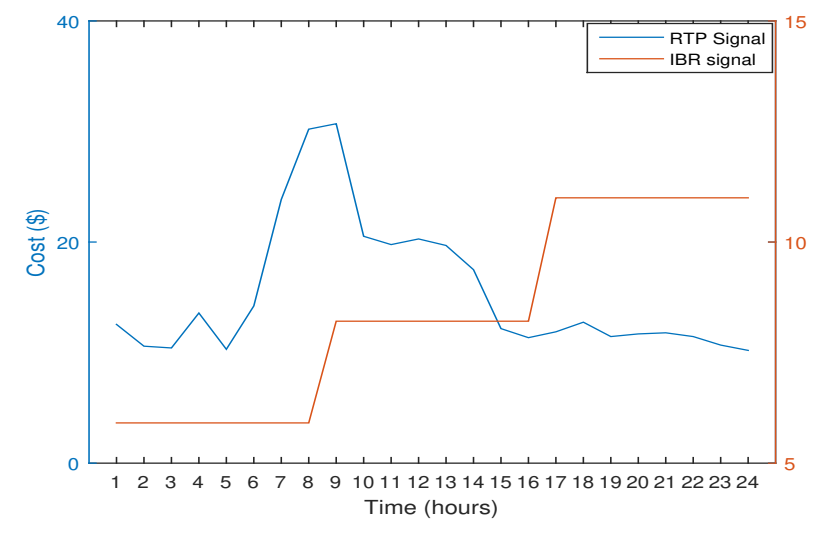

Figure 7. RTP and IBR pricing signal $[72,80]$.

\subsection{Unscheduled Case}

Without using load management programs, these users can be charged more bills due to unscheduled load consumption, without considering market clearing prices. The sample unscheduled and scheduled load patterns without load control parameter have been shown in Figure 8a. Meanwhile, the unscheduled and scheduled load patterns with control parameter are given in Figure $8 \mathrm{~b}$. Figures $8 \mathrm{a}, \mathrm{b}$ and $9 \mathrm{a}, \mathrm{b}$ show the unscheduled peak load and the maximum peak cost reflecting improper scheduling plan because such types of users are willing to pay more bills, without compromising on their comfort level. Figure 10a,b show the total unscheduled cost and the PAR results. It is clear 
from the figures that energy consumption cost with $\zeta$ is comparatively low in all scheduled cases. Furthermore, the cost using RES and IBR+RTP is very much reduced.

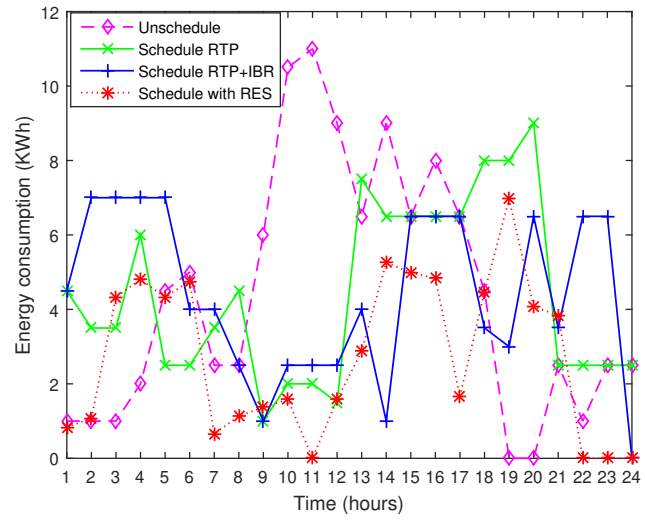

(a)

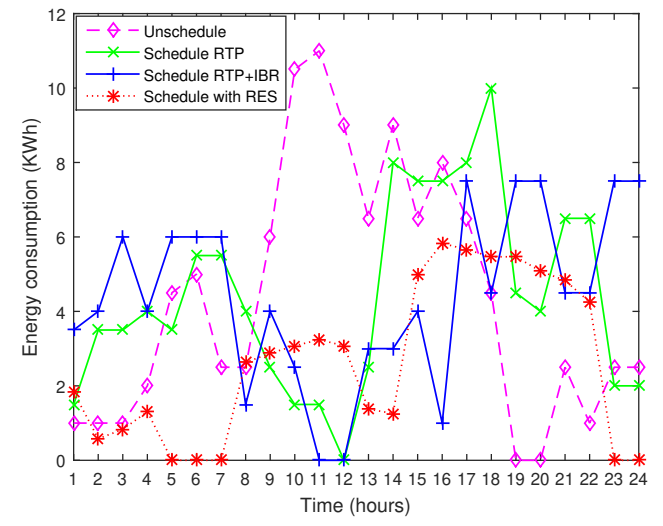

(b)

Figure 8. Unscheduled and scheduled load profiles against various cases; RTP, RTP+IBR and RES. (a) without control parameter; (b) with control parameter.

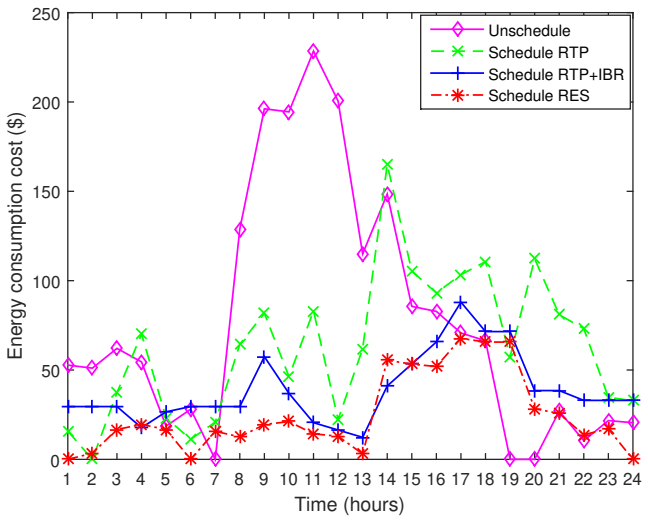

(a)

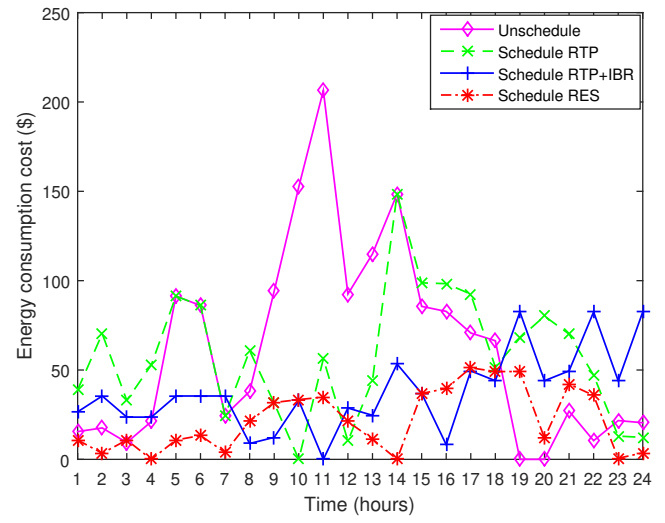

(b)

Figure 9. Unscheduled and scheduled cost profiles against various cases; RTP, RTP+IBR and RES. (a) without control parameter; (b) with control parameter.

\subsection{Scheduled Case with RTP}

In this case, users are considered to have an HEM architecture that is based on scheduling and DSM programs. These types of users are more sensitive to electricity cost as compared to other users. They have proper connectivity with DSM programs and scheduling scheme being offered by utilities and market retailers. In Figure 8a,b, the load and cost curves have shown their maximum values as there is no limit of consuming energy. Figure 8a shows that unscheduled peak load is shifted to off-peak hours. As a result, the cost is reduced, which is shown in Figure 9a. However, the PAR value is comparatively more than other cases. From Figure 9a, it can be seen that the maximum cost is reduced from $217 \$ / \mathrm{KWh}$ to $175 \$ / \mathrm{KWh}$. With the effect of control parameter, the cost is further reduced with maximum user comfort which is shown in Figure $9 \mathrm{~b}$. Thus, the scheduling scheme is more effective for those types of energy users who intend to take part in scheduling programs. In this case, the consumers can reduce their bill; however, the systems' stability can be disturbed due to rebound peaks created due to load shifting. Consequently, the load management programs relying only on RTP seem less feasible where grid reliability is also required along with user satisfaction. For this purpose, a mechanism is needed that can jointly reduce cost and and user discomfort along 
with high system stability. The following section gives a brief discussion about the model using a combined pricing scheme.

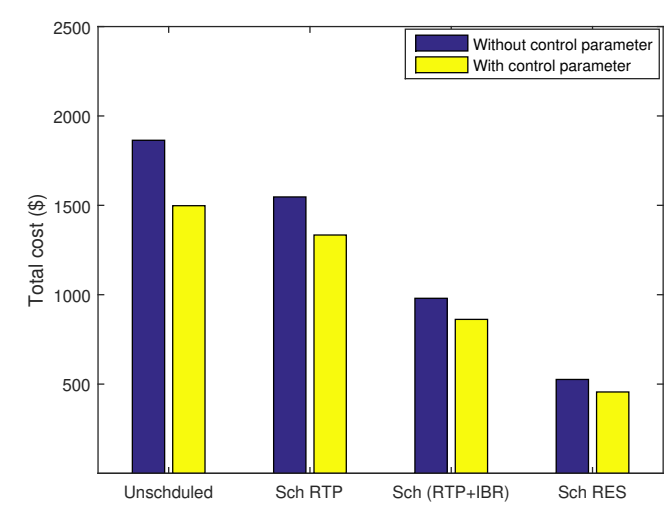

(a)

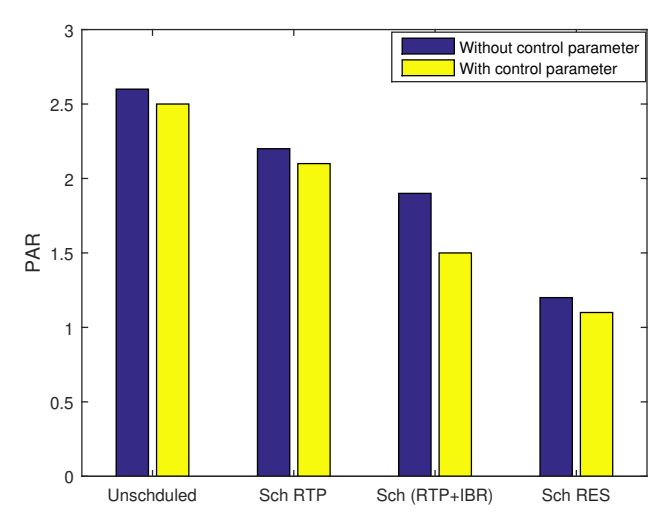

(b)

Figure 10. Total cost and PAR profiles for unscheduled and scheduled cases using; RTP, RTP+IBR and RES options. (a) total cost results for unscheduled, scheduled with RTP, RTP+IBR and RES, without and with control parameter; (b) PAR results for unscheduled, scheduled with RTP, RTP+IBR and RES, without control and with parameter control parameter.

\subsection{Scheduled Case with RTP+IBR}

In this case, we focus on cost and user discomfort minimizations along with reduced PAR. From Figure 9a, it can be visualized that, without utilizing RTP+IBR, the total electricity cost is $\$ 165$, while the cost is further reduced and becomes $\$ 88$ by using a combined pricing plan. Furthermore, the cost and user comfort are achieved with minimum delay time as shown in Figure $9 \mathrm{~b}$. It is clearly shown that, by utilizing RTP+IBR, the cost can be saved up-to 77 \$/day. Furthermore, Figure 10 shows the total cost reduction results. Figure $10 \mathrm{~b}$ demonstrates that PAR has been reduced from 2.68 to 1.5 by using the proposed approach and effect of $\zeta$. Figure 11 gives the user comfort in regards to appliance waiting time. It can be clearly seen that average user comfort in RTP case is comparatively high. This is due to the fact that there is no limit on energy consumption and user comfort. Alternatively, there is a limit on electricity cost using IBR+RTP, as customers will receive more bills if their demand exceeds from given limits. Similarly, Figure 12 shows appliance waiting time in all cases. It is also clearly visible from the figure that the waiting time in RTP cases is comparatively less.

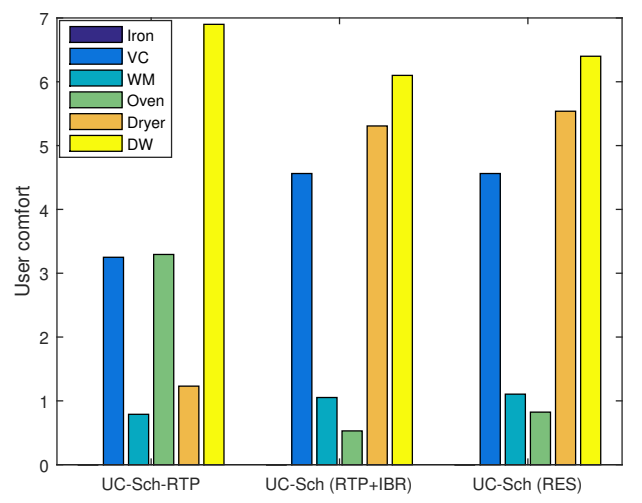

Figure 11. Results of user comfort for scheduled with RTP, RTP+IBR and RES. 


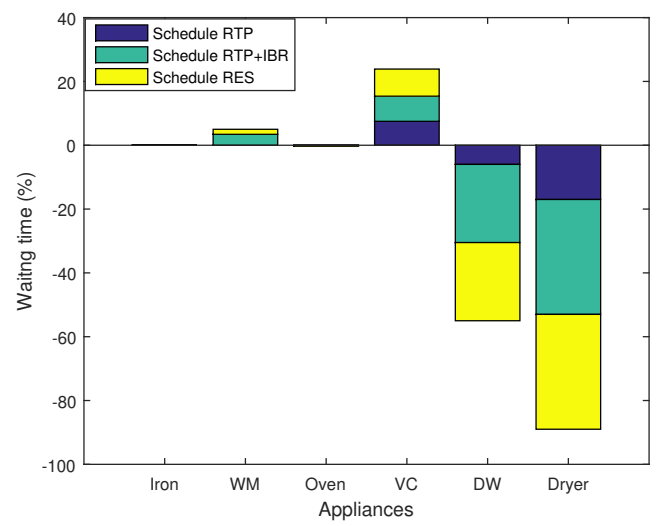

Figure 12. Appliances delay time behavior for scheduled with RTP, RTP+IBR and RES.

\subsection{Scheduled Case with RES}

In this case, we integrate the solar energy in our model to further reduce the cost and user discomfort, while improving the stability of the system. As there is another source of energy, the users do not fully rely on grid energy and can use both sources with the objective of cost minimization. In Figure 9a,b, we can see that with RTP+IBR the total cost is $\$ 88$. However, this value is further reduced and becomes $\$ 51$ with the effect of control parameter $\zeta$ and integration of RES. Figure 10b demonstrates that PAR is also reduced from 1.23 to 1.12, with the integration of RES and maximum user comfort being achieved at the same time. Figure $10 \mathrm{~b}$ also reflects that, by utilizing RES, we can overcome the dependability of users on grid for cost effective benefits as well as decrease PAR with the accomplishment of the most extreme user comfort and minimum delay time.

\subsection{Carbon Footprint}

The emission of harmful gases (i.e., $\mathrm{CO}_{2}$, methane, nitrous oxide and ozone) created direct or indirect impact on human life. Generation of electrical power emits a certain amount of $\mathrm{CO}_{2}$ when a house is heated with electricity. $\mathrm{CO}_{2}$ is also emitted by the production of food and other goods. Therefore, the sum of all emissions is called a carbon footprint, which is induced by activities in a given time frame. Usually, a carbon footprint is calculated for the time period of a year. We discuss three cases: unscheduled, schedule with RTP and schedule with RTP+IBR and compare their mean and variance values. The variance values are 9.3254, 8.8644 and 5.1571 in unscheduled, schedule load with RTP and schedule load with RTP+IBR combined model, respectively. Variance values show reduction in scheduled load with RTP+IBR from 9.3254 to $5.1571 \mathrm{KWh}$. However, RES is introduced to finish $\mathrm{CO}_{2}$ emission effect for reliable environment and system stability. Therefore, all simulation results are listed in Table 7 , which show that carbon emissions are produced with conventional energy generation resources.

Table 7. Overview of all simulation results.

\begin{tabular}{lllll}
\hline Category & Energy (KWh) & Cost (\$) & Cost (\%) & Carbon Footprint (metric tons) \\
\hline Unsch. case & 111.5 & 1860 & 38 & 104.81 \\
\hline Sch. with RTP case & 111.5 & 1130 & 34 & 104.81 \\
\hline Sch. with RTP+IBR case & 111.5 & 619.34 & 17 & 104.81 \\
\hline Sch. with RES case & 690.56 & 604.39 & 11 & 98.2 \\
\hline
\end{tabular}

Unsch. $=$ Unscheduled, Sch. $=$ Scheduled. 


\subsection{Trade-Offs}

In this section, we provide the algorithm execution based on scheduling with RTP and RTP+IBR, and the possible trade-off among various cases depending on constraints and limits. We have investigated three cases: unscheduled, scheduled with RTP and RTP+IBR. An unscheduled case can not provide financial benefits, due to not considering HEM programs. A user can operate their load whenever needed, irrespective of the electricity price. Because the utility sets the prior pricing plan, different electricity costs are obtained for various times. These types of users do not participate in DR programs. They accomplish the most extreme comfort level while compromising on electricity bills.

In the second case, users have intentions to reduce their electricity bill by participating in energy management programs. As these users have first priority to limit the electricity bill, while compromising on their comfort level, the users ideally schedule their appliances and move the load from on peak hours to off peak hours by using HEM. The HEM impels the scheduling plan of users for reduction in electricity consumption cost. A trade-off exists between user cost and comfort because of moving load to low pricing hours.

On the other hand, the third class of users utilized the joint model of RTP+IBR, and shifted their load with minimum delay. The users can get the minimum electricity bill over a little sacrifice on comfort by utilizing an RTP+IBR model. The unscheduled users pay the maximum bill for equal electricity utilized by the smart customers (scheduled RTP+IBR). The smart customers get the most advantages from the RTP+IBR pricing version with an effective HEM model. In a 2nd case, a user compromises on their comfort; however, they pay much less.

In the last case, smart prosumers have both HEM and RES. This magnificence of users has an insightful HEM framework and, along with these strains, it enables the customers to use the grid source for energy as a second source and reduce their bill. Other than RES framework, this case empowers the users to ideally utilize the grid energy.

\section{Conclusions}

This paper presents residential load management approach with integration of RESs and control parameter $\zeta$. Furthermore, in order to balance the overall electricity consumption and waiting cost while enhancing the consumers' savings and preserving their comfort, users have been provided the facility to prioritize comfort over cost by controlling the $\zeta$ parameter. To analyze the performance of the proposed mechanism, we have considered various loads and categorized them on the basis of user requirements. The mathematical models of respective loads have been formulated with respective constraints and limitations. In the first scenario, RTP is used to minimize the energy consumption cost of end users. However, it has also reduced PAR insignificantly, as the major focus was towards cost reduction. In the second scenario, a combined pricing model RTP+IBR has been used to minimize both cost and PAR simultaneously. Eventually, the user comfort is neglected. In the third scenario, we have integrated the RES along with other energy resources to schedule load in accordance with user preferences and electricity price limitations being considered as key constraints. Then, to assess the performance of the proposed mechanism, all test cases are implemented using GA. Furthermore, alongside simulation results, analytical results are also conducted to cross-validate the implemented algorithm, whether the results are optimal or not. It is clear from simulation results that the proposed algorithm has the capability to manage residential load while preserving user comfort. Electricity cost has been reduced from $\$ 228$ to $\$ 51$ and, similarly, PAR has been reduced from 2.68 to 1.12. It is worth noting here that, as we have obtained optimal results, the algorithm has also converged within optimal time. The convergence plots in both RTP and RTP+IBR cases are also given in the paper. Finally, the simulation results are summarized in Table 8. 
Table 8. Comparison of results without and with effect of control parameter.

\begin{tabular}{|c|c|c|c|c|c|c|c|c|c|c|c|c|c|c|}
\hline Parameters & Unsch. & Sch. RTP & Savings & Sch. RTP+IBR & Savings & Sch. RES & Savings & Unsch. with $\zeta$ & Sch. RTP with $\zeta$ & Savings & Sch. RTP+IBR with $\zeta$ & Savings & Sch. RES with $\zeta$ & Savings \\
\hline Per hour cost & 228 & 165 & $72 \%$ & 88 & $38.6 \%$ & 57 & $25 \%$ & 206.5 & 121.8 & $59 \%$ & 82 & $39.6 \%$ & 51 & $24.6 \%$ \\
\hline Total cost & 1864 & 1547 & $83 \%$ & 980 & $52.6 \%$ & 526 & $28 \%$ & 1498 & 1334 & $89 \%$ & 862 & $57 \%$ & 456 & $30 \%$ \\
\hline PAR & 2.68 & 2.2 & $82 \%$ & 1.93 & $72 \%$ & 1.23 & $45.9 \%$ & 2.5 & 2.1 & $84 \%$ & 1.5 & $55.9 \%$ & 1.12 & $44.8 \%$ \\
\hline
\end{tabular}


Author Contributions: Conceptualization, U.A. and M.B.R.; Methodology, M.B.R. Software, U.A.; Validation, M.B.R. and I.A.; Writing-Review and Editing, U.A., M.B.R. and A.S.A.-S.; Visualization, M.B.R.; Supervision, M.B.R.; Project Administration, I.A., A.U.R., A.A. (A. Alzaid), A.A. (A. Alamri); Funding Acquisition, I.A.

Funding: This research work is supported by the University of Malaya under Postgraduate Research Grant (PG035-2016A), Office of Research Innovation and Commercialization (ORIC), the University of Lahore, Lahore, Pakistan and APEC center, ECE department, khalifa University.

Conflicts of Interest: The authors declare no conflict of interest.

\section{References}

1. Nan, S.; Zhou, M.; Li, G. Optimal residential community demand response scheduling in smart grid. Appl. Energy 2018, 210, 1280-1289. [CrossRef]

2. Ghorbel, M.B.; Hamdaoui, B.; Guizani, M.; Mohamed, A. Long-Term Power Procurement Scheduling Method for Smart-Grid Powered Communication Systems. IEEE Trans. Wirel. Commun. 2018, 17, $2882-2892$. [CrossRef]

3. Du, Y.F.; Jiang, L.; Li, Y.; Wu, Q. A Robust Optimization Approach for Demand Side Scheduling Considering Uncertainty of Manually Operated Appliances. IEEE Trans. Smart Grid 2018, 9, 743-755. [CrossRef]

4. Rehmani, M.H.; Reisslein, M.; Rachedi, A.; Erol-Kantarci, M.; Radenkovic, M. Integrating Renewable Energy Resources Into the Smart Grid: Recent Developments in Information and Communication Technologies. IEEE Trans. Ind. Inform. 2018, 14, 2814-2825. [CrossRef]

5. Cao, Z.; Lin, J.; Wan, C.; Song, Y.; Zhang, Y.; Wang, X. Optimal Cloud Computing Resource Allocation for Demand Side Management in Smart Grid. IEEE Trans. Smart Grid 2017, 8, 1943-1955.

6. Erdinc, O.; Tascikaraoglu, A.; Paterakis, N.G.; Eren, Y.; Catalao, J. End-user comfort oriented day-ahead planning for responsive residential HVAC demand aggregation considering weather forecasts. In Proceedings of the 2017 IEEE Power \& Energy Society General Meeting, Chicago, IL, USA, 16-20 July 2017.

7. Jindal, A.; Singh, M.; Kumar, N. Consumption-Aware Data Analytical Demand Response Scheme for Peak Load Reduction in Smart Grid. IEEE Trans. Ind. Electron. 2018, 65, 8993-9004. [CrossRef]

8. Khalid, A.; Javaid, N.; Guizani, M.; Alhussein, M.; Aurangzeb, K.; Ilahi, M. Towards Dynamic Coordination Among Home Appliances Using Multi-Objective Energy Optimization for Demand Side Management in Smart Buildings. IEEE Access 2018, 6, 19509-19529. [CrossRef]

9. Li, T.; Dong, M. Real-Time Residential-Side Joint Energy Storage Management and Load Scheduling with Renewable Integration. IEEE Trans. Smart Grid 2018, 9, 283-298. [CrossRef]

10. Huang, H.; Cai, Y.; Xu, H.; Yu, H. A Multiagent Minority-Game-Based Demand-Response Management of Smart Buildings Toward Peak Load Reduction. IEEE Trans. Comput. Aided Des. Integr. Circuits Syst. 2017, 36, 573-585. [CrossRef]

11. Bollen, M.H.J. Power Quality Concerns in Implementing Smart Distribution-Grid Applications. IEEE Trans. Smart Grid 2017, 8, 391-399. [CrossRef]

12. Chen, C.; Nagananda, K.G.; Xiong, G.; Kishore, S.; Snyder, L.V. A Communication-Based Appliance Scheduling Scheme for Consumer-Premise Energy Management Systems. IEEE Trans. Smart Grid 2013, 4, 56-65. [CrossRef]

13. Good, N. A transactive energy modelling and assessment framework for demand response business cases in smart distributed multi-energy systems. Energy 2018. [CrossRef]

14. Sanjeev, P.; Padhy, N.P.; Agarwal, P. Peak Energy Management Using Renewable Integrated DC Microgrid. IEEE Trans. Smart Grid 2018, 9, 4906-4917. [CrossRef]

15. Dehghanpour, K.; Nehrir, M.H.; Sheppard, J.W.; Kelly, N.C. Agent-Based Modeling of Retail Electrical Energy Markets With Demand Response. IEEE Trans. Smart Grid 2018, 9, 3465-3475. [CrossRef]

16. Nguyen, D.H.; Narikiyo, T.; Kawanishi, M. Optimal Demand Response and Real-Time Pricing by a Sequential Distributed Consensus-Based ADMM Approach. IEEE Trans. Smart Grid 2018, 9, 4964-4974. [CrossRef]

17. Antunes, C.H.; Soares, A.; Gomes, A. An energy management system for residential demand response based on multiobjective optimization. In Proceedings of the 2016 IEEE Smart Energy Grid Engineering (SEGE), Oshawa, ON, USA, 21-24 August 2016; pp. 90-94.

18. Wang, K.; Li, H.; Maharjan, S.; Zhang, Y.; Guo, S. Green Energy Scheduling for Demand Side Management in the Smart Grid. IEEE Trans. Green Commun. Netw. 2018, 2, 596-611. [CrossRef] 
19. Li, D.; Chiu, W.; Sun, H.; Poor, H.V. Multiobjective Optimization for Demand Side Management Program in Smart Grid. IEEE Trans. Ind. Inform. 2018, 14, 1482-1490. [CrossRef]

20. Hu, M.; Xiao, J.-W.; Cui, S.-C.; Wang, Y.-W. Distributed real-time demand response for energy management scheduling in smart grid. Int. J. Electr. Power Energy Syst.2018, 99, 233-245. [CrossRef]

21. Gottwalt, S.; Garttner, J.; Schmeck, H.; Weinhardt, C. Modeling and Valuation of Residential Demand Flexibility for Renewable Energy Integration. IEEE Trans. Smart Grid 2017, 8, 2565-2574. [CrossRef]

22. Hayes, B.; Melatti, I.; Mancini, T.; Prodanovic, M.; Tronci, E. Residential Demand Management Using Individualized Demand Aware Price Policies. IEEE Trans. Smart Grid 2017, 8, 1284-1294. [CrossRef]

23. Keerthisinghe, C.; Verbic, G.; Chapman, A.C. A Fast Technique for Smart Home Management: ADP With Temporal Difference Learning. IEEE Trans. Smart Grid 2018, 9, 3291-3303. [CrossRef]

24. Asgher, U.; Rasheed, M.B.; Awais, M. Demand Response Benefits for Load Management Through Heuristic Algorithm in Smart Grid. In Proceedings of the IEEE Recent Advances in Electrical Engineering (RAEE), PIEAS, Islamabad, Pakistan, 17-18 October 2018.

25. Parizy, E.S.; Bahrami, H.R.; Choi, S. A Low Complexity and Secure Demand Response Technique for Peak Load Reduction. IEEE Trans. Smart Grid 2018. [CrossRef]

26. Huang, X.; Hong, S.H.; Li, Y. Hour-Ahead Price Based Energy Management Scheme for Industrial Facilities. IEEE Trans. Ind. Inform. 2017, 13, 2886-2898. [CrossRef]

27. Al-sumaiti, A.S.; Ahmed, M.H.; Salama, M.M. Smart home activities: A literature review. Electr. Power Compon. Syst. 2014, 42, 294-305. [CrossRef]

28. Ejaz, W.; Naeem, M.; Shahid, A.; Anpalagan, A.; Jo, M. Efficient Energy Management for the Internet of Things in Smart Cities. IEEE Commun. Mag. 2017, 55, 84-91. [CrossRef]

29. Helal, S.A.; Najee, R.J.; Hanna, M.O.; Shaaban, M.F.; Osman, A.H.; Hassan, M.S. On optimal scheduling for smart homes and their integration in smart grids. In Proceedings of the 2017 IEEE 30th Canadian Conference on Electrical and Computer Engineering (CCECE), Windsor, ON, USA, 30 April-3 May 2017; pp. 1-4.

30. Parisio, A.; Wiezorek, C.; Kyntaja, T.; Elo, J.; Strunz, K.; Johansson, K.H. Cooperative MPC-Based Energy Management for Networked Microgrids. IEEE Trans. Smart Grid 2017, 8, 3066-3074. [CrossRef]

31. Mehdizadeh, A.; Taghizadegan, N.; Salehi, J. Risk-based energy management of renewable-based microgrid using information gap decision theory in the presence of peak load management. Appl. Energy 2018, 211, 617-630. [CrossRef]

32. Ma, W.; Wang, J.; Gupta, V.; Chen, C. Distributed Energy Management for Networked Microgrids Using Online ADMM With Regret. IEEE Trans. Smart Grid 2018, 9, 847-856. [CrossRef]

33. Moon, S.; Lee, J. Multi-Residential Demand Response Scheduling With Multi-Class Appliances in Smart Grid. IEEE Trans. Smart Grid 2018, 9, 2518-2528. [CrossRef]

34. Cortes-Arcos, T. Multi-objective demand response to real-time prices (RTP) using a task scheduling methodology. Energy 2017, 138, 19-31. [CrossRef]

35. Fadlullah, Z.M.; Quan, D.M.; Kato, N.; Stojmenovic, I. GTES: An Optimized Game-Theoretic Demand-Side Management Scheme for Smart Grid. IEEE Syst. J. 2014, 8, 588-597. [CrossRef]

36. Maharjan, S.; Zhu, Q.; Zhang, Y.; Gjessing, S.; Basar, T. Dependable Demand Response Management in the Smart Grid: A Stackelberg Game Approach. IEEE Trans. Smart Grid 2013, 4, 120-132. [CrossRef]

37. Adika, C.O.; Wang, L. Autonomous Appliance Scheduling for Household Energy Management. IEEE Trans. Smart Grid 2014, 5, 673-682. [CrossRef]

38. Nunna, H.S.V.S.K.; Battula, S.; Doolla, S.; Srinivasan, D. Energy Management in Smart Distribution Systems With Vehicle-to-Grid Integrated Microgrids. IEEE Trans. Smart Grid 2018, 9, 4004-4016. [CrossRef]

39. Hosen, M.A.; Khosravi, A.; Nahavandi, S.; Creighton, D. Improving the Quality of Prediction Intervals Through Optimal Aggregation. IEEE Trans. Ind. Electron. 2015, 62, 4420-4429. [CrossRef]

40. Saadat, J.; Moallem, P.; Koofigar, H. Training Echo State Neural Network Using Harmony Search Algorithm. Int. J. Artif. Intell. 2017, 15, 163-179.

41. Precup, R.; David, R.; Petriu, E.M. Grey Wolf Optimizer Algorithm-Based Tuning of Fuzzy Control Systems With Reduced Parametric Sensitivity. IEEE Trans. Ind. Electron. 2017, 64, 527-534. [CrossRef]

42. Vrkalovic, S.; Lunca, E.C.; Borlea, I.D. Model-free sliding mode and fuzzy controllers for reverse osmosis desalination plants. Int. J. Artif. Intell. 2018, 16, 208-222.

43. Wu, X.; Hu, X.; Yin, X.; Moura, S.J. Stochastic Optimal Energy Management of Smart Home With PEV Energy Storage. IEEE Trans. Smart Grid 2018, 9, 2065-2075. [CrossRef] 
44. Celik, B.; Roche, R.; Bouquain, D.; Miraoui, A. Decentralized neighborhood energy management with coordinated smart home energy sharing. IEEE Trans. Smart Grid 2018, 9, 6387-6397.

45. Park, L.; Jang, Y.; Cho, S.; Kim, J. Residential Demand Response for Renewable Energy Resources in Smart Grid Systems. IEEE Trans. Ind. Inform. 2017, 13, 3165-3173. [CrossRef]

46. Keles, C.; Alagoz, B.B.; Kaygusuz, A. Multi-source energy mixing for renewable energy microgrids by particle swarm optimization. In Proceedings of the 2017 International Artificial Intelligence and Data Processing Symposium (IDAP), Malatya, Turkey, 16-17 September 2017; pp. 1-5.

47. Wen, Z.; Neill, D.O.; Maei, H. Optimal Demand Response Using Device-Based Reinforcement Learning. IEEE Trans. Smart Grid 2015, 6, 2312-2324. [CrossRef]

48. Vardakas, J.S.; Zorba, N.; Verikoukis, C.V. Power demand control scenarios for smart grid applications with finite number of appliances. Appl. Energy 2016, 162, 83-98. [CrossRef]

49. Li, C.; Yu, X.; Yu, W.; Chen, G.; Wang, J. Efficient Computation for Sparse Load Shifting in Demand Side Management. IEEE Trans. Smart Grid 2017, 8, 250-261. [CrossRef]

50. El Shafie, A.; Niyato, D.; Hamila, R.; Al-Dhahir, N. Impact of the Wireless Network's PHY Security and Reliability on Demand-Side Management Cost in the Smart Grid. IEEE Access 2017, 5, 5678-5689. [CrossRef]

51. Kim, S.J.; Giannakis, G.B. Scalable and Robust Demand Response With Mixed-Integer Constraints. IEEE Trans. Smart Grid 2013, 4, 2089-2099.

52. Werminski, S. Demand side management using DADR automation in the peak load reduction. Renew. Sustain. Energy Rev. 2017, 67, 998-1007. [CrossRef]

53. Aktas, A. Experimental investigation of a new smart energy management algorithm for a hybrid energy storage system in smart grid applications. Electr. Power Syst. Res. 2017, 144, 185-196. [CrossRef]

54. Alkaabi, S.S.; Zeineldin, H.H.; Khadkikar, V. Short-Term Reactive Power Planning to Minimize Cost of Energy Losses Considering PV Systems. IEEE Trans. Smart Grid 2018. [CrossRef]

55. Bao, Z. Optimal Multi-Timescale Demand Side Scheduling Considering Dynamic Scenarios of Electricity Demand. IEEE Trans. Smart Grid 2018. [CrossRef]

56. Zhao, B. Energy Management of Multiple-Microgrids based on a System of Systems Architecture. IEEE Trans. Power Syst. 2018. [CrossRef]

57. Mortazavi, H.; Mehrjerdi, H.; Saad, M.; Lefebvre, S. Distribution power factor monitoring in presence of high RES integration using a modified load encroachment technique. IET Renew. Power Gener. 2018, 12, 851-858. [CrossRef]

58. Huang, C.; Wang, L.; Yeung, R.S.; Zhang, Z.; Chung, H.S.; Bensoussan, A. A Prediction Model-Guided Jaya Algorithm for the PV System Maximum Power Point Tracking. IEEE Trans. Sustain. Energy 2018, 9, 45-55. [CrossRef]

59. Kivimäki, J.; Kolesnik, S.; Sitbon, M.; Suntio, T.; Kuperman, A. Design Guidelines for Multiloop Perturbative Maximum Power Point Tracking Algorithms. IEEE Trans. Power Electron. 2018, 33, 1284-1293. [CrossRef]

60. Al-Sumaiti, A.S.; Ahmed, M.H.; Salama, M. Residential Load Management Under Stochastic Weather Condition in Developing Countries. Electr. Power Components Syst. 2014, 42, 1452-1473. [CrossRef]

61. Javaid, N.; Naseem, M.; Rasheed, M.B.; Mahmood, D.; Khan, S.A.; Alrajeh, N.; Iqbal, Z. A new heuristically optimized Home Energy Management controller for smart grid. Sustain. Cities Soc. 2017, 34, $211-227$. [CrossRef]

62. Rasheed, M.B.; Javaid, N.; Imran, M.; Khan, Z.A.; Qasim, U.; Vasilakos, A. Delay and energy consumption analysis of priority guaranteed MAC protocol for wireless body area networks. Wirel. Netw. 2017, 23, 1249-1266. [CrossRef]

63. Elghitani, F.; Zhuang, W. Aggregating a Large Number of Residential Appliances for Demand Response Applications. IEEE Trans. Smart Grid 2018, 9, 5092-5100. [CrossRef]

64. Lizondo, D.; Rodriguez, S.; Will, A.; Jimenez, V.; Gotay, J. An Artificial Immune Network for Distributed Demand-Side Management in Smart Grids. Inf. Sci. 2018, 438, 32-45. [CrossRef]

65. Liu, R.-S.; Hsu, Y.-F. A scalable and robust approach to demand side management for smart grids with uncertain renewable power generation and bi-directional energy trading. Int. J. Electr. Power Energy Syst. 2018, 97, 396-407. [CrossRef]

66. Tushar, M.H.K.; Zeineddine, A.W.; Assi, C. Demand-Side Management by Regulating Charging and Discharging of the EV, ESS, and Utilizing Renewable Energy. IEEE Trans. Ind. Inform. 2018, 14, 117-126. [CrossRef] 
67. Bui, V.; Hussain, A.; Kim, H. A Multiagent-Based Hierarchical Energy Management Strategy for Multi-Microgrids Considering Adjustable Power and Demand Response. IEEE Trans. Smart Grid 2018, 9, 1323-1333. [CrossRef]

68. Zhao, Z.; Lee, W.C.; Shin, Y.; Song, K. An Optimal Power Scheduling Method for Demand Response in Home Energy Management System. IEEE Trans. Smart Grid 2013, 4, 1391-1400. [CrossRef]

69. Luo, C.; Huang, Y.; Gupta, V. Stochastic Dynamic Pricing for EV Charging Stations With Renewable Integration and Energy Storage. IEEE Trans. Smart Grid 2018, 9, 1494-1505. [CrossRef]

70. Baronti, F.; Vazquez, S.; Chow, M. Modeling, Control, and Integration of Energy Storage Systems in E-Transportation and Smart Grid. IEEE Trans. Ind. Electron. 2018, 65, 6548-6551. [CrossRef]

71. Kadri, R.L.; Boctor, F.F. An efficient genetic algorithm to solve the resource-constrained project scheduling problem with transfer times: The single mode case. Eur. J. Oper. Res. 2018, 265, 454-462. [CrossRef]

72. Gong, D.; Sun, J.; Miao, Z. A Set-Based Genetic Algorithm for Interval Many-Objective Optimization Problems. IEEE Trans. Evol. Comput. 2018, 22, 47-60. [CrossRef]

73. Abushnaf, J.; Rassau, A. Impact of energy management system on the sizing of a grid-connected PV/Battery system. Electr. J. 2018, 31, 58-66. [CrossRef]

74. Yaagoubi, N.; Mouftah, H.T. User-Aware Game Theoretic Approach for Demand Management. IEEE Trans. Smart Grid 2015, 6, 716-725. [CrossRef]

75. Rasheed, M.B.; Javaid, N.; Ahmad, A.; Awais, M.; Khan, Z.A.; Qasim, U.; Alrajeh, N. Priority and delay constrained demand side management in real-time price environment with renewable energy source. Int. J. Energy Res. 2016, 40, 2002-2021. [CrossRef]

76. Chen, W.-H.; Wu, P.-H.; Lin, Y.-L. Performance optimization of thermoelectric generators designed by multi-objective genetic algorithm. Appl. Energy 2018, 209, 211-223. [CrossRef]

77. Moreno, J.; Lopez, M.A.; Martinez, R. A new algorithm for solving all the real roots of a nonlinear system of equations in a given feasible region. Numer. Algor. 2018,1-32. [CrossRef]

78. Time has Arrived for Time Variant Pricing, but What Kind? Available online: http://www.menloenergy. com/?p=349 (accessed on 23 August 2018).

79. Askarzadeh, A. A Memory-Based Genetic Algorithm for Optimization of Power Generation in a Microgrid. IEEE Trans. Sustain. Energy 2018, 9, 1081-1089. [CrossRef]

80. Energy Market and Operational Data. Available online: http://mis.nyiso.com/public/pdf/damlbmp/ 20181214damlbmp_zone.pdf (accessed on 12 May 2018).

(C) 2018 by the authors. Licensee MDPI, Basel, Switzerland. This article is an open access article distributed under the terms and conditions of the Creative Commons Attribution (CC BY) license (http:// creativecommons.org/licenses/by/4.0/). 